\title{
A comparison of the molecular organization of genomic regions associated with resistance to common bacterial blight in two Phaseolus vulgaris genotypes
}

\section{Gregory Perry ${ }^{1 *}$, Claudia DiNatale ${ }^{2}$, Weilong Xie $^{3}$, Alireza Navabi ${ }^{3}$, Yarmilla Reinprecht ${ }^{1}$, William Crosby ${ }^{2}$, Kangfu Yu ${ }^{4}$, Chun Shi ${ }^{4}$ and K. Peter Pauls ${ }^{1}$}

\author{
${ }^{1}$ Department of Plant Agriculture, University of Guelph, Guelph, ON, Canada \\ ${ }^{2}$ Department of Biological Sciences, University of Windsor, Windsor, ON, Canada \\ ${ }^{3}$ Agriculture and Agri-Food Canada, c/o Department of Plant Agriculture, University of Guelph, Guelph, ON, Canada \\ ${ }^{4}$ Greenhouse and Processing Crops Research Centre, Agriculture and Agri-Food Canada, Harrow, ON, Canada
}

\section{Edited by:}

Georgina Hernandez, Centro de Ciencias Genomicas-Universidad Nacional Autonoma de Mexico, Mexico

Reviewed by:

Francesca Sparvoli, Institute of Agricultural Biology and

Biotechnology, Italy

Oswaldo Valdes-Lopez, University of Wisconsin-Madison, USA

\section{${ }^{*}$ Correspondence:}

Gregory Perry, Department of Plant Agriculture, University of Guelph, 50 Stone Road East, Guelph, N1G 2W1 ON, Canada e-mail:perryg@uoguelph.ca
Resistance to common bacterial blight, caused by Xanthomonas axonopodis pv. phaseoli, in Phaseolus vulgaris is conditioned by several loci on different chromosomes. Previous studies with OAC-Rex, a CBB-resistant, white bean variety of Mesoamerican origin, identified two resistance loci associated with the molecular markers PV-CTT001 and SU91, on chromosome 4 and 8 , respectively. Resistance to CBB is assumed to be derived from an interspecific cross with Phaseolus acutifolius in the pedigree of OAC-Rex. Our current whole genome sequencing effort with OAC-Rex provided the opportunity to compare its genome in the regions associated with CBB resistance with the v1.0 release of the $P$. vulgaris line G19833, which is a large seeded bean of Andean origin, and (assumed to be) CBB susceptible. In addition, the genomic regions containing SAP6, a marker associated with $P$. vulgaris-derived CBB-resistance on chromosome 10, were compared. These analyses indicated that gene content was highly conserved between G19833 and OAC-Rex across the regions examined (>80\%). However, fifty-nine genes unique to OAC Rex were identified, with resistance gene homologues making up the largest category (10 genes identified). Two unique genes in OAC-Rex located within the SU91 resistance QTL have homology to $P$. acutifolius ESTs and may be potential sources of CBB resistance. As the genomic sequence assembly of OAC-Rex is completed, we expect that further comparisons between it and the G19833 genome will lead to a greater understanding of CBB resistance in bean.

Keywords: common bacterial blight, next generation sequencing, disease resistance, comparative genomics, phaseolus vulgaris

\section{INTRODUCTION}

Phaseolus vulgaris L. (common dry bean), a member of the Fabacaea family, is the most important food legume in the world and is widely cultivated in Asia, North and South America and Africa, The Phaseolus genus is comprised of over 50 members, with $P$. vulgaris being the most commonly cultivated species. The primary gene pool of $P$. vulgaris is comprised of two geographically isolated pools: the Mesoamerican, and the Andean (Evans, 1973; Koening and Gepts, 1989; Koening et al., 1990; Singh et al., 1991; Debouck et al., 1993), which are distinguished by differences in seed size and color that define different market classes, although, in general, the beans of Mesoamerican origin have smaller seeds than those of Andean origin (Singh et al., 1991). The Mesoamerican pool is considered to be ancestral to the Andean pool, and there is evidence of a bottleneck in genetic diversity occurring years ago during the establishment of the Andean pool (Bitocchi et al., 2012).

Common bacterial blight (CBB) is a major foliar and seedborne disease affecting bean production throughout the world. The disease is caused by the pathogen Xanthomonas axonopodis pv. phaseoli (Xap, for review see Hayward and Waterston, 1965;
Starr, 1981; Leyns et al., 1984; Buell, 2002; Yun et al., 2006; Perry and Pauls, 2012). The pathogen is endemic in the soil of most regions where dry beans are cultivated, and the ability of the pathogen to colonize the seeds of infected plants greatly increases the risk of pathogen carry-over from year to year.

Immunity to Xap has not been observed in $P$. vulgaris, but complete resistance has been observed in members of the secondary and tertiary gene pools such as Phaseolus coccineus (Park and Dhanvantari, 1987; Miklas et al., 1994) and Phaseolus acutifolius (for review see Park and Dhanvantari, 1987; Singh and Schwartz, 2010). OAC-Rex (Parker, 1985; Scott and Michaels, 1992; Michaels et al., 2006), HR45 and HR67 (Park and Dhanvantari, 1994) were developed from interspecific crosses between $P$. vulgaris and $P$. acutifolius. In particular, OAC-Rex, which was registered as the first bacterial blight resistant cultivar in Canada in 2002 (Michaels et al., 2006), derives its resistance from the P. acutifolius line PI 440795. Resistance loci have been associated with molecular markers $P v$ CTT001 (GI:169360), SU91 (GI:156072919), BNG71 and BNG21 in OAC Rex (Tar'an et al., 2001; Shi et al., 2012; Durham et al., 2013). 
The breeding lines HR67 and HR45 were derived from XAN 159, which was developed from a cross between ICI Piajo and P. acutifolius PI 319443 (Parker, 1985). Two major CBB resistance Quantitative Trait Loci (QTL) associated with the markers UBC420 and SU91 have been identified in these lines (Yu et al., 2004). Epistatic interaction between the SU91- and UBC420associated QTL has been observed. When only one marker is present, the resistance is mild to moderate in the field, but when both are present, strong resistance is observed (Shi et al., 2011; Durham et al., 2013).

In addition to the $P$. acutifolius-derived $\mathrm{CBB}$ resistance, some $P$. vulgaris-derived resistance was found in lines descended from the Great Northern landrace that is associated with the SAP6 marker (GI:218137924) on chromosome 10 (for review see Gepts et al., 2008). Although the level of resistance provided by this QTL is low, it appears to act epistatically with SU91 (Vandermark et al., 2008), indicating that similar interactions may be occurring between gene products of SU91, SAP6, and UBC420. In contrast, epistatic interactions have not been observed between SU91 and Pv-CTT001 (Durham, 2011).

Although the development of molecular markers has aided research on $\mathrm{CBB}$ resistance in beans, and facilitated the selection of new $\mathrm{CBB}$ resistant varieties, previously the lack of genome sequence information for bean has hindered the identification of the resistance genes associated with the markers. In contrast with many other crop plants, genomic resources for $P$. vulgaris were relatively limited before the release of the genomic sequence of the Andean breeding line G19833 (P. vulgaris v1.0, DOE-JGI and USDA-NIFA, http://www.phytozome.net/commonbean). Prior to September 2012, there were just over 148,000 ESTs listed in GenBank along with a limited number of molecular markers (Ramirez et al., 2005). Schuleter et al. (2008) sequenced the ends of 41,717 BAC clones from a BAC library of the G19833 line. At the time, it was the most significant collection of $P$. vulgaris sequence information, including over $62 \mathrm{Mb}$ of sequence data and accounting for $\sim 9.54 \%$ of the total $P$. vulgaris genome. In addition, 1536 randomly selected BAC clones were fully sequenced using a shotgun method. The sequence information derived from the end-sequencing and the shotgun sequencing was analyzed using the basic local alignment search tool (BLAST) and compared to sequence data from A. thaliana, M. truncatula, and L. japonicus. These comparisons indicated that approximately $49.2 \%$ of the bean genome is composed to repetitive sequence and only $29.3 \%$ of the genome contains functional genes. The breakdown of the genic regions was remarkably similar between the shotgun sequenced clones and the BAC end sequences, with approximately $38 \%$ of the genes coding for proteins involved in cellular processes and 33\% involved in metabolic processes. The sequence information from the shotgun sequencing was more useful for predicting the functions of genes, due to the longer reads, but the low cut-off levels used as part of the assembly and annotation process limited the ability of this study to accurately predict gene function (for review see Gepts et al., 2008; Schuleter et al., 2008).

Comparative genomics in plants is still a relatively new field, and has been limited by the number of completed genome sequences available. Previous studies examining the consequences of interspecific hybridization have largely used molecular markers to quantify the degree of introgression in given populations, predominantly between cultivars and their wild relatives (Arnold et al., 2003; Riesberg et al., 2003; Gill et al., 2011; Andrew et al., 2012; Hufford et al., 2013). SNP marker studies in Zea mays, Pinus pumila, and Helianthus petiolaris, have indicated that hybridization rates can vary along chromosomes. Direct comparisons of gene content in plants have been generally limited to model organisms such as Arabidopsis thaliana, as part of the 1000 Arabidopsis genomes project (Cao et al., 2011; Schneeberger et al., 2011). Work involving leguminous species has centered on Glycine max, and comparative genetic analyses between the Williams 82 genome, and the LD09-15087a breeding line was used to highlight changes in the Rhg1 QTL, which is involved in resistance to Heterodera glycines. This study was able to identify resistance genes based on copy number variation and expression studies of resistant and susceptible cultivars (Cook et al., 2012).

With the release of the V1.0 G19833 sequence, genomic comparisons are now possible between the $P$. vulgaris genotypes. This genome was primarily assembled using the Roche 454 platform (Wheeler et al., 2008), combined with Sanger end sequencing of a bacterial artificial chromosome library of G19833. The V1.0 release is covers a total of $521.1 \mathrm{Mb}$, arranged in 708 scaffolds, and 41,391 contigs, covering all 11 bean chromosomes. In-silico gene annotation has resulted in 27,197 loci, containing 31,638 presumptive genes. The genomic sequence is available for download at www.phytozome.net.

Genomic sequencing of OAC-Rex is currently ongoing, with initial assemblies yielding contigs in the megabase range that collectively account for $83 \%$ of the G19833 sequence (DiNatale et al., unpublished results). The two datasets represent one of the first opportunities to compare large genomic regions between $P$. vulgaris genotypes and the first to compare the G19833 genome with a line that has an interspecific cross in its pedigree.

The goal of the current study is to compare the genes in the regions surrounding the $P v$-CTT001, SU91 and SAP6 markers for CBB resistance candidates between OAC-Rex and G19833. The assumption is that although the order, orientation, and identity of most of the gene annotations are likely to be conserved between the two genomes, the OAC-Rex will genome will have some unique genes that will be of interest for their possible involvement in CBB-resistance. In addition, the comparison should provide insights into the effects of introgression genome structure.

\section{MATERIALS AND METHODS DNA ISOLATION AND SEOUENCING}

Genomic DNA was isolated from intact nuclei using a modified protocol of Zhang et al. (1995), Leaf tissue ( $10 \mathrm{~g}$ ) was frozen in liquid nitrogen and ground to a fine powder using a mortar and pestle. The ground leaf tissue was divided into two $5 \mathrm{~g}$ aliquots and placed into $50 \mathrm{ml}$ Oakridge tubes with $100 \mathrm{ml}$ of ice-cold $1 \times$ Homogenization Buffer (HB; $0.01 \mathrm{M}$ Trizma base, $0.08 \mathrm{M} \mathrm{KCl}$, $0.01 \mathrm{M}$ EDTA, $1 \mathrm{mM}$ spermidine- $\mathrm{HCl}, 1 \mathrm{mM}$ spermine- $\mathrm{HCl}+$ $0.15 \% \beta$-mercapthoethanol $+0.5 \%$ Triton X-100 + 2\% PVP-40; [Sigma, St. Louis MO]). The samples were gently mixed with a glass rod until homogeneous. Following a 20 min incubation on ice, during which the samples were swirled every $2 \mathrm{~min}$, they were 
filtered through 2 layers of cheese cloth and one layer of Mira cloth to remove large debris.

The tubes were centrifuged at $1800 \mathrm{~g}$ for $20 \mathrm{~min}$ at $4^{\circ} \mathrm{C}$ and the supernatant was discarded. The pellets were washed three times with cold Wash Buffer (WB; 1XHB, 0.5 M sucrose, 0.5\% Triton X-100) and were resuspended with a fine paintbrush in the tube. For the first wash, an additional $30 \mathrm{ml}$ of WB was added to the homogenate, and the samples filtered through two layers of sterile cheese cloth and one layer of Mira cloth. The tubes were centrifuged at $1200 \mathrm{~g}$ for $20 \mathrm{~min}$ at $4^{\circ} \mathrm{C}$ and the supernatant discarded. For further washes ( 5 were required), only $5 \mathrm{ml}$ of buffer WB were used, and the homogenate was not filtered prior to centrifugation. During the washing steps the color of the pellet changed from green to white. For the final wash, the two tubes were combined together into a total volume of $10 \mathrm{ml}$. Buffer WB was added to a final volume of $30 \mathrm{ml}$ and the samples were centrifuged at $1200 \mathrm{~g}$ for $20 \mathrm{~min}$ The pellets were resuspended in $0.5 \mathrm{ml}$ of buffer HB ( $50 \mu \mathrm{l} / \mathrm{g}$ tissue $)$ using a fine paint brush and placed on ice.

The intact nuclei were processed using a Qiagen DNeasy Plant Kit (Qiagen, Valencia CA). The samples were processed according to the manufacturer's instructions. After the final ethanol wash, the samples were resuspended in $600 \mu \mathrm{l}$ of TE buffer $(10 \mathrm{mM}$ Tris pH 8.0 and $1 \mathrm{mM}$ EDTA).

The DNA was sequenced using the Illumina HiSeq platform at the Center for Applied Genomics, Toronto, Ontario. Two mate pair libraries, 2.5 and $7 \mathrm{~kb}$ were prepared using the manufacturer's protocol for $50 \mathrm{bp}$ read lengths. Shotgun sequencing using pairedend, $100 \mathrm{bp}$ reads was performed to give an overall sequence depth greater than 100 (DiNatale et al., unpublished results).

Scaffolding and contig assembly was performed at the University of Windsor using SOAP2 de novo and ABYSS. For details regarding the assembly and annotation of the OAC-Rex genome, please refer to our companion publication "Assembly and annotation of a short-read draft genome sequence for P. vulgaris cv. OAC-REX” (DiNatale et al., Unpublished results).

\section{NUCLEOTIDE ANALYSES}

Sequences from G19833 and OAC-Rex containing the markers of interest were identified through BLAST analysis using BioEdit (http://www.mbio.ncsu.edu/bioedit/bioedit.html). For the SNP markers (Table 1), the only nucleotide variation permitted was at the polymorphism site, and all other nucleotide identities must be conserved (120/121 bp). For the Pv-CTT001, SU91 and SAP6 markers, an $e$-value of 0.00 was required for the match to be considered valid.

\section{SEQUENCE ANNOTATION AND GENOMIC COMPARISONS}

The sequence data was examined for open reading frames using FGENESH (http://www.softberry.org), with the Medicago gene model. The predicted gene sequences were BLASTed to the NCBI nucleotide and EST databases. Predicted protein sequences were compared using tBLAST. All comparisons were made using the CLC Genomics Workbench built-in BLAST functionality. Significant homologies were defined by having $E$-values $<\mathrm{E}^{-30}$ for nucleotide comparisons and $E$-values $<E^{-20}$ for amino acid sequences, and were plotted onto the assembled contigs.
Functional characterization of predicted genes was accomplished by examining the resulting BLAST homologies, and categorizing them into one of 8 groups based on previously characterized genes (Schuleter et al., 2008): 1. Unknown/No Homology, 2. Hypothetical Predicted Protein, 3. Defense/Signaling/Stress, 4. Hormone Response, 5. Transcription/Translation Factor, 6. Structural Component, 7. Metabolism and 8. Transposable Element. In the event of two predicted functions, the result with the highest homology was generally selected with the exception of BLAST homologies to BAC clones, or other genomic survey sequence results, as these do not represent functional gene characterizations.

Syntany analyses were conducted in CLC Genomics Workbench using the integrated BLAST functionality with an internal database containing the predicted cDNA sequences. The sequences were compared between the G19833 and OAC-Rex lines only within a single chromosome range. Homologies were considered significant with $E$-values $<\mathrm{E}^{-50}$, or when nucleotide homology was greater than $90 \%$ for short gene calls, defined by CDS sequences less than $300 \mathrm{bp}$.

Protein analyses were performed using the predicted mRNA sequences from FGeneSH, and translated into amino acid sequences using the CLC Genomics Workbench standard model. Protein domains were predicted using the Pfam database (Finn et al., 2010). Transmembrane domains were predicted using the TMHMM web server (Krogh et al., 2001; http://www.cbs.dtu.dk/ services/TMHMM/).

\section{GENOMIC RESOURCES}

Genomic sequence data for the unannotated V1.0 G19833 release was obtained from Phytozome (McClean et al., Unpublished Results; http://www.phytozome.net/).

Sequences for the BeanCAP single nucleotide polymorphism (SNP) markers was obtained with the assistance of Dr. Perry Creegan (USDA, Beltsville Agricultural Research Center, MD, USA).

Genomic sequence data for OAC-Rex will be available from the Applied Bean Genomics and Bioproducts website (http://www. beangenomics.ca).

\section{RESULTS}

\section{OTL AND CONTIG IDENTIFICATION}

The pseudochromosome sequences from G19833 were interrogated with the sequences for the molecular markers $P v$-CTT001, SAP6 and SU91. The $P v$-CTT001 marker was found at the beginning chromosome 4 in G19833, starting at 517,577 bp and ending at 517,741 bp (Figure 1A). The SAP6 marker was found on chromosome 10 in G19833, starting at 39,938,699 bp and ending at 39,939,569 bp (Figure 1B). In both cases, the marker sequences only had one significant homology in the genome assembly for G19833. The SU91 marker was not found in the G19833 sequence. However, a SU91-associated region in the G19833 sequence was selected using the c00126p592970 and c00322p82935 markers, which were previously mapped to the SU91 QTL in HR45 (Figure 1C, Xie et al., unpublished results; Shi et al., 2012). It starts at 58,994,870 bp and ends at 59,444,870 bp. The SU91 marker was previously identified in a $450 \mathrm{~kb}$ region 
Table 1 | BeanCAP Marker locations in G19833.

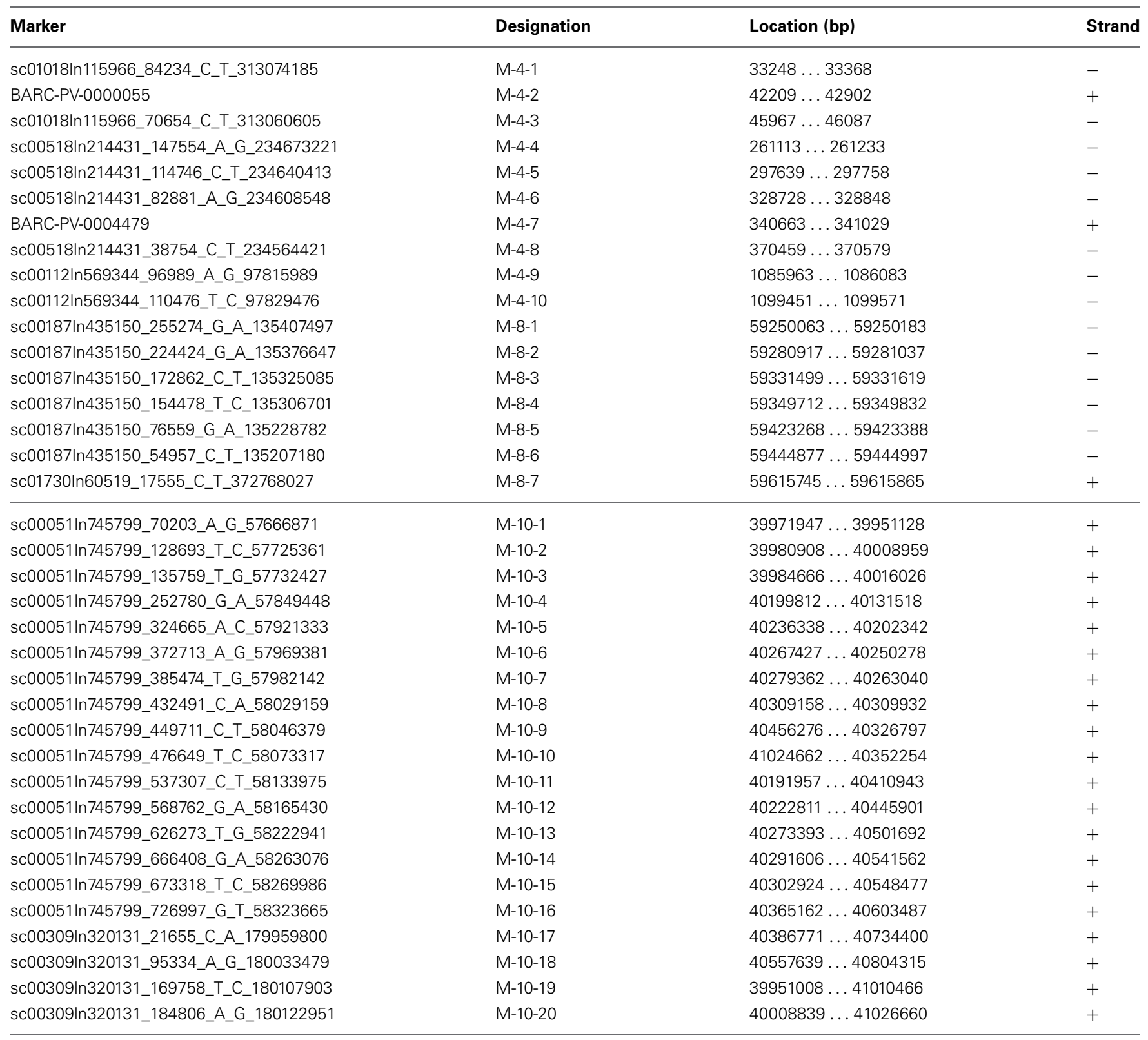

on chromosome 8 in HR45, which is flanked by the markers c00126p592970 and c00322p82935 (Xie et al., unpublished results). A larger region, from the c00126p592970 marker to the end of chromosome 8, corresponding to a $666 \mathrm{~kb}$ fragment, was selected from the G19833 sequence (58,994,870-59,662,532 bp) for further comparisons.

The genomic region covered by the $P v$-CTT001 marker was highly conserved in G19833 and OAC Rex lines, but the sequence that would be amplified from the marker primers in G19833 would be expected to be 12 bp longer than from the OAC Rex sequence because of the presence of four additional CTT repeats, starting at $517633 \mathrm{bp}$, in the former (Figure 2A).

The SU91 marker was not found in the G19833 sequence (Figure 2B), and interestingly, although the G1833 line does not have the sequence corresponding to the forward primer for the SAP6 marker, it does contain the reverse primer sequence and the adjacent sequences are very similar between OAC Rex and G19833 (Figure 2C). The location of the SAP6 fragment in G19833 and OAC-Rex is in the same region as has been described for lines derived from the Great Northern \#1 Sel 27 (for review see Miklas et al., 2003; Singh and Schwartz, 2010).

Once the markers in G19833 were identified, larger sections of the chromosomes $(667.7 \mathrm{~kb}$ to $1.1 \mathrm{Mb})$ were selected to account for the estimated recombination distances between the markers and potential resistance genes (for review see Perry and Pauls, 2012). These regions were examined for other markers and gene sequences that could be used to identify contigs in the OAC-Rex assembly. In particular, the regions were annotated 


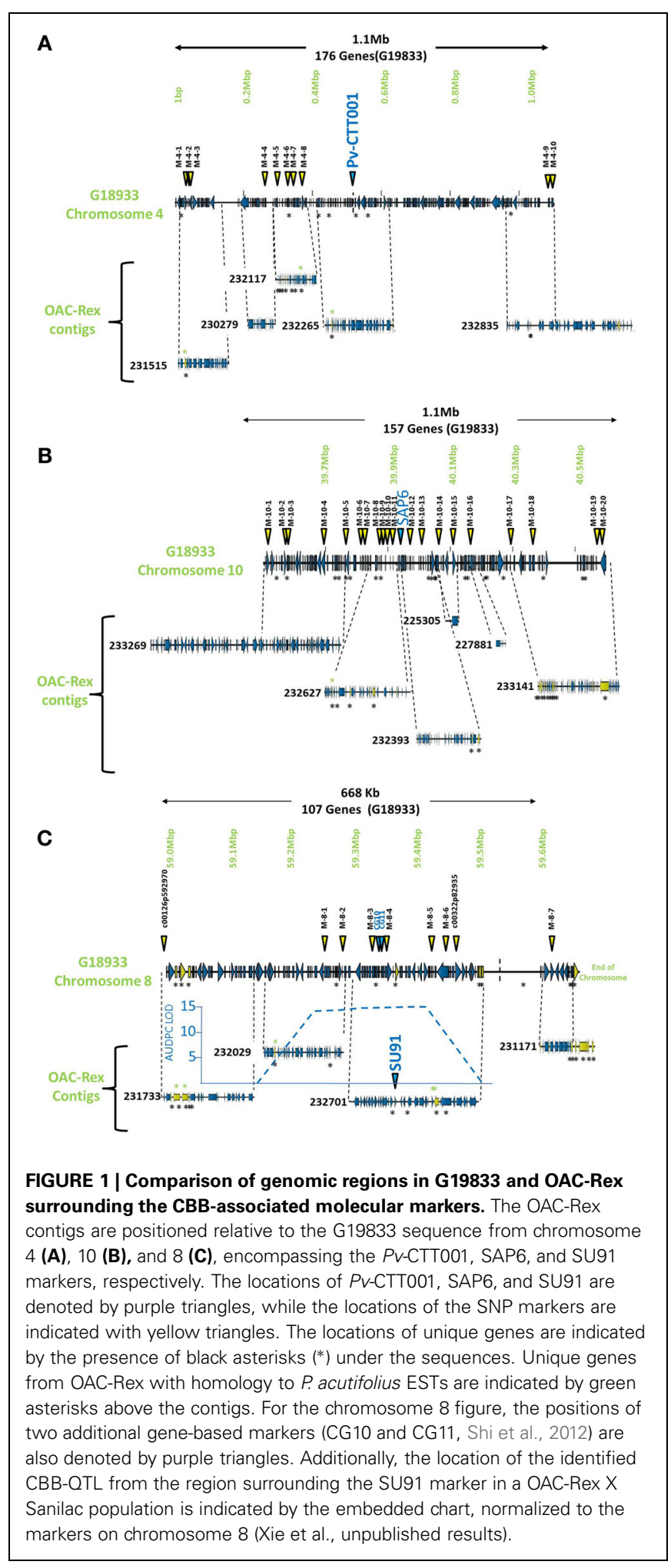

using FGENESH, and populated with SNP markers from the BeanCAP collection (Hyten et al., 2010; Perry Creegan, Personal Communication) (Figure 1; Table 1).

The G19833 chromosome 4 fragment was found to contain 171 genes and 10 SNP markers, covering the full length of the fragment (Figure 1A) giving an annotated gene density of 0.16 genes/kb. Interestingly, the SNP markers were heavily skewed toward the beginning and end of the selected region, with 8 of the SNPs occurring in the first $370 \mathrm{~kb}$ of the fragment, and the last 2 found starting at $1.09 \mathrm{Mb}$. The intervening region was found to contain only the $P v$-CTT001 marker at $517,577 \mathrm{bp}$, with no additional landmarks found in the latter half of the selection.

The chromosome 10 fragment contained 130 predicted genes, with an overall gene density of 0.12 genes/kb (Figure 1B). This was the lowest gene density for the three fragments, although it can partially be explained by the presence of a $100 \mathrm{~kb}$ unknown nucleotide region, starting at $910 \mathrm{~kb}$. The 20 SNP markers were located across the whole region, with only limited clustering of two markers near the beginning of the fragment.

The fragment from chromosome 8 contained 105 genes and 7 SNP markers (Figure 1C). The gene density of 0.16 genes $/ \mathrm{kb}$ is similar to that found for the other fragments. As with the chromosome 4 fragment, the distribution of the SNP markers was somewhat skewed, with the markers being evenly distributed starting $250 \mathrm{~kb}$ into the fragment. Only the c00126p592970 marker was found at the start of the region, with no other landmarks present until the M-8-1 SNP marker located at 59,248,128 bp. The terminal end of the fragment was also found to contain a long region of unknown nucleotides (N) spanning approximately $150 \mathrm{~kb}$ $(59,511,657$ bp to $59,661,425 \mathrm{bp})$, which limited the comparisons that could be made in this region.

The markers identified in the three regions were used to interrogate the K41 assembly of the OAC-Rex sequence (www. beangenomics.ca), and yielded 16 contigs, ranging from 21.1 to $476.8 \mathrm{~kb}$ in size. The chromosome 4 region was populated by 5 OAC-Rex contigs $(231515,230279,23117,232265$, and 232835), covering a total distance of $701 \mathrm{~kb}$, and containing 114 genes. Because contig 232835 extends beyond the range of the $1.1 \mathrm{Mb}$ fragment; only 100 of these genes were contained within the G19833 region examined. Four of the contigs, 231515 (105,837 bp), 230279 (67,213 bp), 232117 (139,956 bp) and $232265(150,801 \mathrm{bp})$, were aligned sequentially along the first 615,105 bp of the G19833 sequence and contained the first 9 SNP markers. The Pv-CTT001 marker was found in contig 232265. All the contigs, with the exception of 230279 , contained multiple markers, which facilitated their positioning along the G19833 sequence. The 237,587 bp OAC-Rex contig 232835 contained the remaining 2 SNP markers and aligned with the terminal end of the G19833 sequence.

The region surrounding the SAP6 marker on chromosome 10 was homologous to 6 OAC-Rex contigs, namely: 233269 (476,805 bp), 232627 (195,818 bp), 232393 (165,172 bp), 225305 (21,147 bp), 227881 (36,196 bp), and 233141 (359,578 bp). They contained 160 genes. However 42 genes were found outside of the G19833 region on contigs 232269 and 233141. All of the contigs contained multiple SNP markers, (2 and 6 markers per contig).

The region surrounding the SU91 marker was populated by 4 contigs, 231733 (117,016 bp), 232029 (133,816 bp), 232701 (207,708 bp) and 231171 (91,949 bp), covering a total distance of $550 \mathrm{~kb}$ and containing 96 predicted genes. Contigs 231733 and 231171 contained single SNP markers, c00126p592970 and M-8-7, respectively; while the remaining contigs each contained 


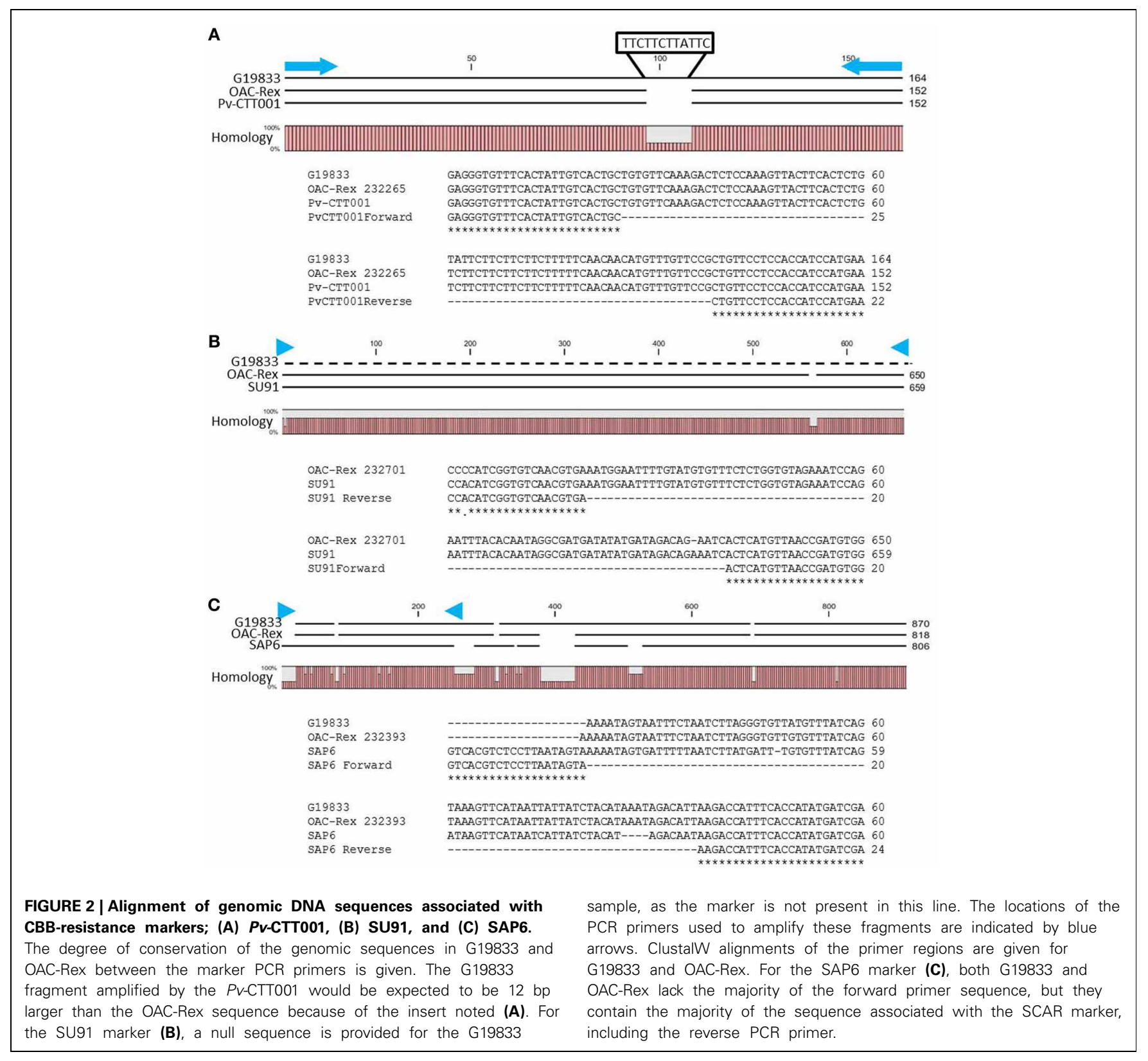

between 2 to 4 markers. No contigs were found within the region from $59,511,657$ to $59,661,425 \mathrm{bp}$, due to the presence of a large number of unknown $(\mathrm{N})$ nucleotides $(P$. vulgaris v0.9, DOE-JGI and USDA-NIFA, http://www.phytozome.net/ commonbean). A previous characterization of a $65 \mathrm{~kb}$ HR45 BAC contig library (32H6), containing the SU91 marker resulted in the development of additional molecular markers (CG10 and CG11) for this region (Shi et al., 2012; Figure 1C) that were used to identify the corresponding region in G19833 and OAC-Rex (G19833 c8:59,333,799-59,396,160 and 232701:94178-160157 bp, respectively).

\section{GENE CONTENT}

The predicted genes in the three $\mathrm{CBB}$ marker-associated regions for the OAC-Rex and G19833 lines were grouped into functional categories for comparison (Figure 3). The annotations from chromosome 4 of the G19833 line indicated that the largest category of the predicted genes fell into the Unknown or Hypothetical protein categories; accounting for 8.2 and $32.2 \%$ of the total, respectively. Among the genes to which a specific roles could be ascribed, those functioning in Metabolism and Defense/Signaling/Stress constituted the two largest categories, with 27.5 and $20.47 \%$ of the total, respectively. The remaining genes coded for a collection of structural components and transcription/translation regulators (4.7 and 4.1\%) and a small number $(2.9 \%)$ of transposable elements.

A similar gene distribution was found among the 5 contigs from OAC-Rex associated with Pv-CTT001. Genes falling into the Unknown and Hypothetical categories accounted for $30.7 \%$ of the total. As in the G19833 line, Metabolism and 
Defense/Signaling/Stress genes were the largest groups of genes with identifiable function, making up 35.1 and $21.9 \%$ of the total, respectively. Similar to G18833, the remaining genes were structural genes $(7.0 \%)$, transcription/translation factor genes $(4.4 \%)$, and transposable elements $(0.9 \%)$.

The gene annotations for the chromosome 8 segment associated with SU91 in G19833 indicated that general Metabolism genes accounted for the single largest category, with $38.1 \%$ of the total gene content. This was followed by the Unknown or Hypothetical genes, with a combined total of $28.6 \%$. The remaining genes were categorized as Defense/Signaling/Stress, Transcription/Translation and Structural related, and accounted for $15.4,7.6$, and $10.5 \%$ of the total, respectively. The groupings were very similar for the genes in the OAC-Rex contigs associated with SU91. Specifically the distribution among categories was: $40.6 \%$ Metabolism, 23.9\% combined Unknown and Hypothetical, $18.8 \%$ Defense/Signaling/Stress related, $4.1 \%$ Transcription/Translation factors, and 7.3\% Structural genes.

The region from chromosome 10 of line G19833 had Unknown or Hypothetical genes accounting for $36.1 \%$ of the total. This value was lower in the OAC-Rex chromosome 10 contigs associated with SAP6 (35\%), however, it still represented the largest group of genes in the identified OAC-Rex contigs. The values for other categories of genes were also

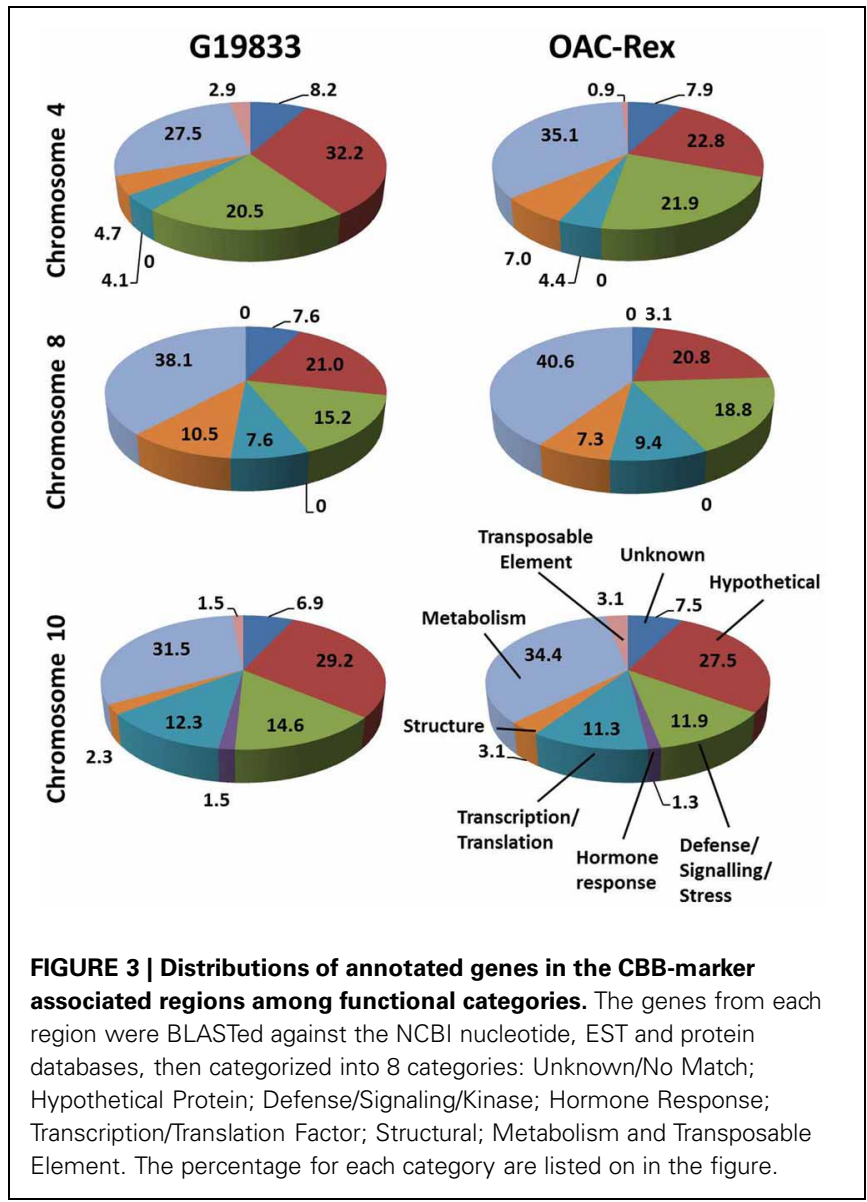

comparable between the two lines. The number of Metabolism and Defense/Signaling/Stress genes in OAC-Rex was 34.4 and $11.9 \%$, respectively, compared to 31.5 and $14.6 \%$, respectively for G19833. There was little variability seen among the other gene categories between the gene annotations in the G19833 and OAC-Rex fragments.

\section{COMPARISON OF CHROMOSOME GENE ORGANIZATION}

In addition to general gene content, the physical gene order and orientation were well-conserved between G19833 and OAC-Rex over all three chromosome regions. Where differences did occur, it was generally not in the form of large spans containing multiple consecutive genes, but instead unique genes were found interspersed between conserved gene regions, normally with no more than 3 unique genes in tandem, and covering regions of less than $15,000 \mathrm{bp}$. Exceptions to this were found on chromosome 8 (Figure 4), with two clusters found. The first was at the start of contig 231733 encompassing 4 CC-NBS-LRR genes from 10135 to $33238 \mathrm{bp}$. The second was found on the terminal end of chromosome 8 , where a cluster of 6 additional genes on OAC-Rex contig 231171 were found when compared to G19833.

Outside of these regions, the novel genes found in G19833 and OAC-Rex were interspersed over most of the annotated regions within generally conserved genetic content. Of the 171 genes annotated for the G19833 sequence from chromosome 4, 68 were not found in OAC-Rex contigs. Due to the absence of any markers or unique gene features between 621,481 and 974,996 bp, no corresponding OAC-Rex contigs were found within this region. A reference assembly of this region using the raw shotgun reads from OAC-Rex indicated that OAC Rex has homologous sequences covering $69 \%$ of the 60 genes that are present in the G19833 line in this region, but they do not coalesce into a single contig and are consequently not shown. Also, it is not possible to positively conclude that the OAC Rex sequences detected in this analysis are from this region and not another region of the OAC-Rex genome. Outside of this region, only 7 unique genes were present in G19833. Unique genes were also present in OAC-Rex, with 11 annotated genes having no analogue in the G19833 line (Table 2). Many of these genes could be categorized as Defense/Signaling/Kinases. However, only 3 genes

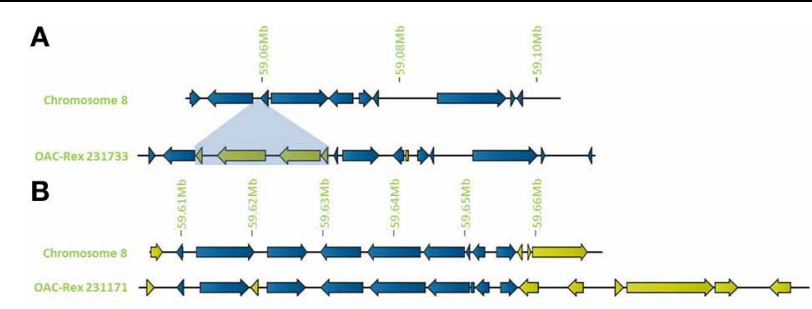

FIGURE 4 | Distribution of unique genes in G19833 and OAC-Rex. (A) Comparison of chromosome 8 showing the insertion of a cluster of unique genes around $59.06 \mathrm{Mb}$ and a single unique gene at $59.08 \mathrm{Mb}$.

(B) Comparison of a section of chromosome 8 showing positions of unique genes in G19833 and OAC-Rex at the end of chromosome 8. Unique gene clusters in both G19833 and the OAC-Rex contig 231171 were found, with 3 unique genes and 6 unique genes, respectively. 
Table 2 | Unique genes identified in OAC-Rex.

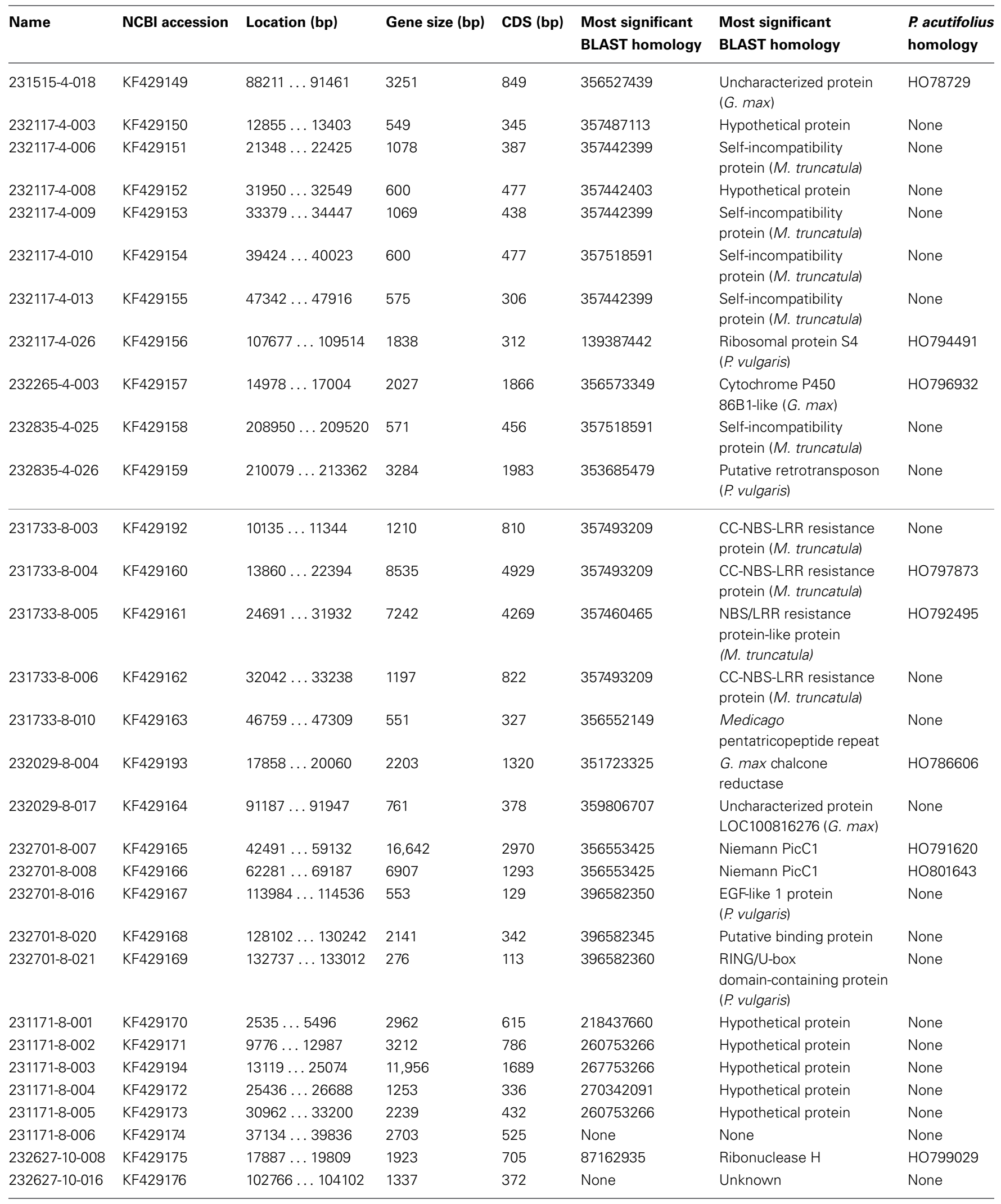


Table 2 | Continued

\begin{tabular}{|c|c|c|c|c|c|c|c|}
\hline Name & NCBI accession & Location (bp) & Gene size (bp) & CDS (bp) & $\begin{array}{l}\text { Most significant } \\
\text { BLAST homology }\end{array}$ & $\begin{array}{l}\text { Most significant } \\
\text { BLAST homology }\end{array}$ & $\begin{array}{l}\text { P acutifolius } \\
\text { homology }\end{array}$ \\
\hline 232627-10-018 & KF429195 & $109610 \ldots 114230$ & 4621 & 972 & 356558954 & $\begin{array}{l}\text { Cation/calcium exchanger } \\
\text { 4-like }\end{array}$ & None \\
\hline 232627-10-021 & KF429177 & $149640 \ldots 149815$ & 176 & 126 & 312059257 & Hypothetical protein & None \\
\hline 232393-10-016 & KF429178 & $118287 \ldots 119145$ & 859 & 330 & 356522402 & Hypothetical protein & None \\
\hline 232393-10-020 & KF429179 & $156523 \ldots 159933$ & 3411 & 312 & None & Unknown & None \\
\hline 233141-10-002 & KF429180 & $6415 \ldots 11763$ & 5349 & 3366 & 51854301 & Putative polyprotein & None \\
\hline 233141-10-003 & KF429181 & $13594 \ldots 20654$ & 7061 & 4101 & 353685479 & Putative retrotransposon & None \\
\hline $233141-10-004$ & KF429182 & $24619 \ldots 25453$ & 835 & 378 & 356522390 & Suppressor of npr-1 & None \\
\hline 233141-10-006 & KF429196 & $31169 \ldots 33542$ & 2374 & 636 & 356558721 & $\begin{array}{l}\text { Putative disease } \\
\text { resistance protein }\end{array}$ & None \\
\hline 233141-10-007 & KF429183 & $37228 \ldots 39059$ & 1832 & 1023 & 356558721 & $\begin{array}{l}\text { Putative disease } \\
\text { resistance protein }\end{array}$ & None \\
\hline 233141-10-011 & KF429184 & $64258 \ldots 65884$ & 1627 & 708 & 356522390 & Suppressor of npr-1 & None \\
\hline 233141-10-012 & KF429185 & $66591 \ldots 71982$ & 5,392 & 708 & 120529942 & Hypothetical protein & None \\
\hline $233141-10-013$ & KF429186 & $73306 \ldots 74730$ & 1,425 & 570 & 356522390 & Suppressor or npr-1 & None \\
\hline $233141-10-014$ & KF429187 & $74786 \ldots 76925$ & 2,140 & 354 & 356522390 & Suppressor or npr-2 & None \\
\hline $233141-10-033$ & KF429188 & $240188 \ldots 242639$ & 2,452 & 285 & 255640830 & Hypothetical protein & None \\
\hline $233141-10-034$ & KF429189 & $246548 \ldots 248053$ & 1,506 & 555 & 312034114 & Hypothetical protein & None \\
\hline 233141-10-036 & KF429190 & $256995 \ldots 257918$ & 924 & 384 & 357509013 & Hypothetical protein & None \\
\hline
\end{tabular}

(231515-4-018, 232117-4-26, and 232265-4-003) were found to have homology to $P$. acutifolius EST accessions from a drought stressed P. acutifolius library (LIBEST_026709, VSU-ARS-L15; Narina and Bhardwaj, unpublished).

On the SAP6-associated fragments from chromosome 10, 30 genes from G19833 were not found in the OAC-Rex contigs. The 5 contigs from OAC-Rex spanned the entire region, with only 11 genes located in regions not covered by OAC-Rex contigs. Interestingly, 18 genes from the OAC-Rex contigs were unique (Table 2). Although the Defense/Signaling/Kinase category only accounted for $11.9 \%$ of the overall gene content in OAC-Rex, they made up $33 \%$ of the unique gene content. Only a single unique gene was found to have homology to the $P$. acutifolius, with 232627-10-008 having homology to HO799029. Gene order and orientation was less conserved between OAC-Rex and G19833 for the SAP6 associated regions, when compared to the regions from chromosome 4 and 8 .

The sequence surrounding the SU91 marker on chromosome 8 encodes 105 genes in line G19833, with a region between $59,511,657$ and 59,661,425 bp that was mostly Ns. This prevented the identification of corresponding contigs from OAC-Rex to populate this region, although most of the G18933 region is covered with 4 OAC-Rex contigs. Overall, there were 12 unique genes in G19833 and 18 unique genes in OAC-Rex (Figure 1C, Table 2). In OAC-Rex, no function could be ascribed to 7 of these genes, however, 11 genes did have homology to previously characterized or predicted proteins, including: 4 resistance gene candidates (231733-8-003, 231733-8-004, 231733-8-005, and 231733-8006), a pentatricopeptide repeat (231733-8-010), a chalcone reductase (232029-8-004), two Niemann Pick like gene (2327018-007 and 232701-8-008), an EGF1-like gene (232701-8-016), and a RING-U-box domain containing protein (232701-8-020).
Encompassed by the QTL for CBB-resistance the OAC-Rex sequence appeared to contain a mutation/rearrangement of gene G19833-8-80 in G19833, which is homologous to a Niemann Pick cholesterol transporter from Homo sapiens (Carstea et al., 1997). It appears that this gene is split into two genes in OAC-Rex. Both genes in OAC-Rex (232701-8-007 and 232701-8-008) had homology to the Niemann Pick cholesterol transporter. An alignment of these genes relative to the G19833-8-080 and Niemann Pick-type genes from G. max and M. truncatula (Figures 5, 6A), showed that the OAC-Rex genes appear to have been derived from different regions of the G19833-8-080 gene, with 2327018-007 representing the region from the N-terminus to 900 aa, and 232701-8-008 representing the 1100 aa to the C-terminus. The intervening space between these two genes is over $3000 \mathrm{bp}$ in length in the OAC Rex genome. Both genes have stop codons and polyA signals.

The OAC-Rex Niemann Pick-like genes were also homologous to $P$. acutifolius ESTs. Gene 232701-8-008 was highly homologous to HO801643 (Figure 7A), an EST from LIBEST 026709, a $P$. acutifolius library derived from drought-stressed leaf tissue from line VSU-ARS-L15. The match covers $81 \%$ of the predicted gene sequence, with 1052 out of $1239 \mathrm{bp}$ conserved. The homology for 232701-8-007 was not as clear, as no singe EST covered the entire length of the gene. Rather, two ESTs, HO791620 and HO787932 (Figure 7B), were found to be homologous to over half of the predicted gene sequence, with an overall homology of 99\% in these regions. The ESTs do not appear to be complete, as they both lack start and stop codons (for review see Nakamoto, 2009).

A Pfam domain search of both of the Niemann Pick-like genes from OAC-Rex, as well as the gene from G19833 showed that the two OAC-Rex genes appear to encompass separate regions 


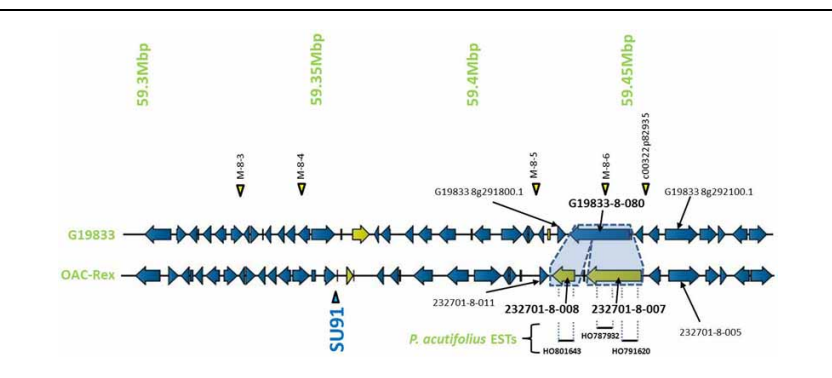

FIGURE 5 | Comparison of the regions surrounding the SU91 marker in OAC-Rex contig 232701 with the corresponding sequence from G19833 chromosome 8. Unique genes are marked in yellow, and the two genes (232701-8-007 and 232701-8-008) that are homologous with the G19833 Niemann Pick transporter gene are highlighted for comparison.

232701-8-007 has homology with two P. acutifolius ESTs (HO787932 and HO791620) while 232701-8-008, has homology to a single $P$. acutifolius (EST, HO801643). Highly conserved genes bordering this region in G19833 and OAC-Rex are labeled. The location of molecular markers are indicated with triangles above and below the sequence.

of the G19833, G. max and M. truncatula genes (Figure 6; XM_003545009 and XM_003618061, respectively). The 2327018-007 gene encodes a protein with 8 transmembrane domains and contains a sterol sensing domain, while 232701-8-008, encodes a protein containing 5 transmembrane domains, but no other identifiable domains. The transmembrane domains shared some homology to the 7-transmembrane (7TM) domain proteins from Arabidopsis and Hordeum vulgare, which have been associated with susceptibility to fungal and bacterial pathogens through the $M L O$ genes in previous studies (Piffanelli et al., 2004; Consonni et al., 2006). Analysis of the predicted proteins with the 7TMRminer program (Lu et al., 2009; http:// bioinfolab.unl.edu/emlab/7tmr), indicated that none of the $P$. vulgaris proteins have exact matches to this motif. In particular, neither of the OAC-Rex genes contained the required 7 transmembrane domains, while the gene from G19833 was found to contain too many (12 potential transmembrane domains identified). But the genes did have some characteristics in common with 7TMR proteins, indicated by positive matches for the nonalignment-based comparisons [Support Vector Machine (SVM) -amino acid, SVM-dipeptide and partial least squares regressionauto/cross-covariance], However, these comparisons are not considered to be as strong support for the 7TMR motif as the alignment-based comparisons (Lu et al., 2009). The similarity of the predicted proteins from $P$. vulgaris to 7TMR proteins from Arabidopsis (AGB1) and barley (MLO1-15), and Niemann Pick proteins from Arabidopsis, G. max, and M. truncatula was also examined using nearest neighbor analysis. The resulting dendrogram showed that the genes from Phaseolus cluster more strongly with the Niemann Pick proteins than 7TMR proteins (Figure 8). However, the relationship is weakest for the OAC-Rex genes.

A comparison of the exon/intron structures of the $P$. vulgaris Niemann Pick-like genes to those in other species indicated that, although the exon structure between the OAC-Rex genes and the G19833 gene are highly conserved, the structures are only marginally conserved between G19833 P. vulgaris, G. max, and Medicago. A BLAST analysis indicated that there is only one copy of the Niemann Pick gene in G19833, three in G. max and one in Medicago (data not shown). An analysis of the surrounding genes in G19833 and OAC-Rex (Figure 9) indicates that the exon structure is conserved across species in these genes, and that only the Niemann Pick genes seem to possess this divergent exon/intron structure. Although expression data from P. vulgaris was not available at this time, an examination of the Medicago Gene Atlas (Benedito et al., 2008; http://mtgea. noble.org/v3/) indicated that the Niemann Pick analogues from M. truncatula (Medtr5g099070.1) and G. $\max$ (Glyma14g00400.1 and Glyma02g48070.1) appear to be expressed in all indexed tissues (data not shown).

The role of EGF1-Like genes (232701-8-016) in plants is poorly understood, although there is some evidence that they are related to wall associated protein kinases (WAKs; Wagner and Kohorn, 2001; Verica and He, 2002). However, the small size of the annotated gene in P. vulgaris (Gene: 553bp, CDS: $129 \mathrm{bp}$ ), would indicate that this gene does not encode a functional protein (Silva and Goring, 2002). No corresponding gene analogue was found in G19833.

Outside of the mapped resistance QTL, 5 genes in OAC-Rex from the 231733 contig (231733-8-002, 231733-8-003, 231733$8-004,231733-8-005$, and 231733-8-006) were found to have homology to coiled coil-nucleotide- binding site-leucine rich repeat (CC-NBS-LRR) resistance genes from $M$. truncatula, although the shortness of genes 231733-8-003 and 231733-8-006 (at 1210 and $1197 \mathrm{bp}$, respectively) suggest that they may not be functional resistance genes. The region containing the four genes, 231733-8-003, 231733-8-004, 231733-8-005, and 2317338-006, appears to represent an insertion event in OAC-Rex, after 231733-8-002 and corresponding to the region after G198338-009 in G19833 (Figure 10A). Genes 231733-8-002, 231733-8004, and 231733-8-005 were homologous to P. acutifolius ESTs (HO792495, HO797873, and HO792495, respectively).

Only gene G19833-8-009 in G19833 was found to be homologous to the CC-NBS-LRR type resistance genes in this region, and an alignment of putative proteins encoded by G19833 G198338-009 and genes 231733-8-002, 231733-8-004, and 231733-8-005 from contig 231733 (Figure 10B) showed that all 4 genes are closely related. A Pfam domain search indicated that G19833 G19833-8-009 and OAC-Rex 231733-8-002 were the most closely related. Both had 9 LRR domains arranged in a very similar pattern. OAC-Rex 231733-8-004 and 231733-8-005 have 12 and 13 LRR domains, respectively, with a significantly different distribution compared to 231733-8-002 and G19833 G19833-8-009. All four genes appear to share a common motif of 5 LRR regions starting at approximately 700 aa, although the positions and spacing's of these repeats vary from gene to gene. The greatest level of variability was found in the C-terminal region, where OAC-Rex 231733-8-004 and 231733-8-005 possess several additional LRR regions when compared to G19833 G19833-8-009.

In addition to the LRR domains, a nucleotide binding site was found in the N-terminal regions of G19833 G19833-8-009, OAC-Rex 231733-8-004, and 231733-8-005. This feature was not found in OAC-Rex 231733-8-002, although the overall homology between all the genes in this region is over $90 \%$. 

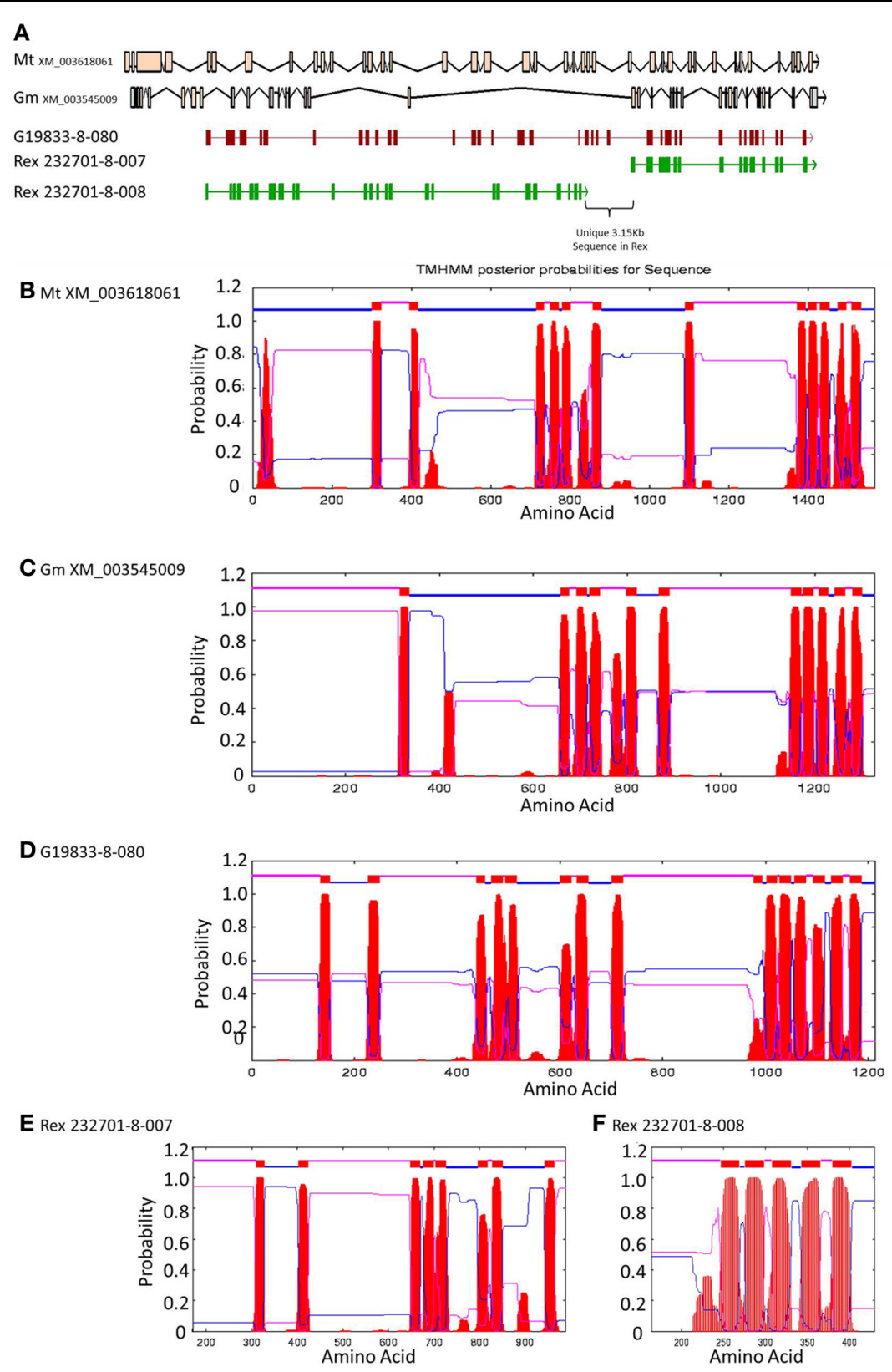

FIGURE 6 | Comparisons of Niemann Pick-like genes from G. $\max$ $M$. truncatula, and G19833 $P$ vulgaris and genes in the same locus in OAC-Rex. (A) The exon/intron structures of the genes. Secondary structure probabilities determined by TMHMM Server v. 2.0 for M. truncatula (B), G. $\max$ (C), G19833 (D), OAC-Rex gene 232701-8-007 (E), and OAC-Rex gene 232701-8-008 (F).

\section{DISCUSSION}

\section{GENE CONTENT AND ORIENTATION ARE CONSERVED BETWEEN} G19833 AND OAC-REX

Although the current study compared genomic regions in beans of Mesoamerican and Andean origin, and the former included an interspecific cross with $P$. acutifolius in its pedigree, the overriding finding was that there is a high degree of similarity in overall gene identity, order, and orientation between OAC-Rex and G19833. This similarity is particularly striking because the regions that were chosen for the comparison were thought to be different because they are associated with resistance to CBB in OAC-Rex, introduced through introgression, and there is no report of resistance in G19833. In fact, all three regions associated with the markers for $\mathrm{CBB}$ resistance were largely conserved between the two lines, even in the case of the SU91 marker, whose sequence is almost entirely absent from the G19833 sequence. These results indicate that, even in regions where molecular markers associated with specific introgression events occur, the overall frequency 


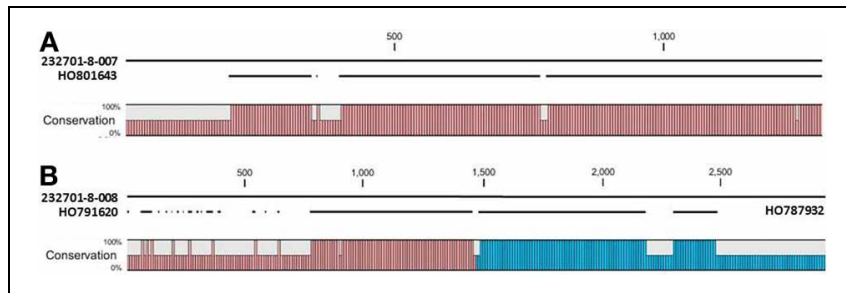

FIGURE 7 | Alignments of $P$ acutifolius ESTs with the predicted CDS sequence from the Niemann Pick locus in OAC-Rex. The percent conservation between three accessions from a drought stressed P. acutifolius library (Narina and Bhardwaj, unpublished) and the OAC-Rex genes 232701-8-007 (A) and 232701-8-008 (B) are shown. EST HO801643 contained a stop codon at the same position as the OAC-Rex gene, neither HO0791620 nor HO787932 were complete and did not contain start or stop codons. Their positions in the alignment are denoted by red and blue bars in the Conservation graph, respectively.

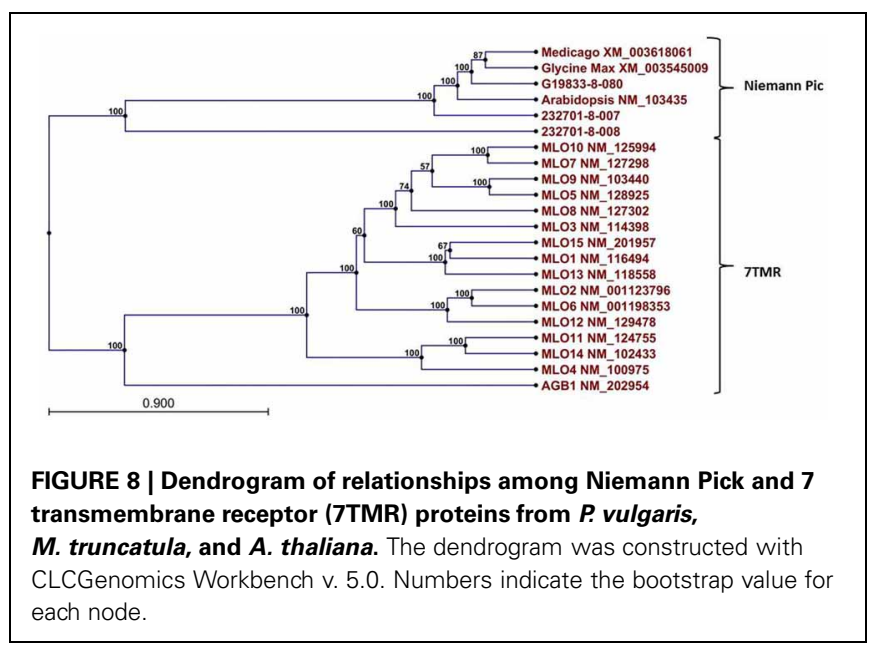

of unique gene transfer is low. This was true for the regions that had unique (SU91, Pv-CTT001) and shared (SAP6) markers. Although the susceptibility of genomic regions to introgression varies along chromosomes (Andrew et al., 2012; Hufford et al., 2013), the amount of new genetic material, including unique genes will most likely still be low, even in regions with high levels of hybridization as assayed by dense marker screens. To identify unique genes, it appears that direct sequence comparisons across large genomic regions are needed to accurately assess the introgression of new genes into genotypes. In plants derived from more recent hybridization events, percentage of new material may be higher (Baack and Rieseberg, 2007), but in a cultivated variety, such as OAC-Rex, which was backcrossed several times to P. vulgaris lines, the unique gene content is relatively low.

We also found that the unique gene content generally consisted of individual or paired genes, interspersed among the conserved regions. However, exceptions to this did occur in chromosomes 8 , which had larger gene clusters containing four or more unique genes. In the case of the cluster at the end of G19833 chromosome 8 , and in contig 231171 in OAC-Rex, the unique genes represent the end of the annotated chromosome in both regions, and no homologies could be found for any of these genes. The
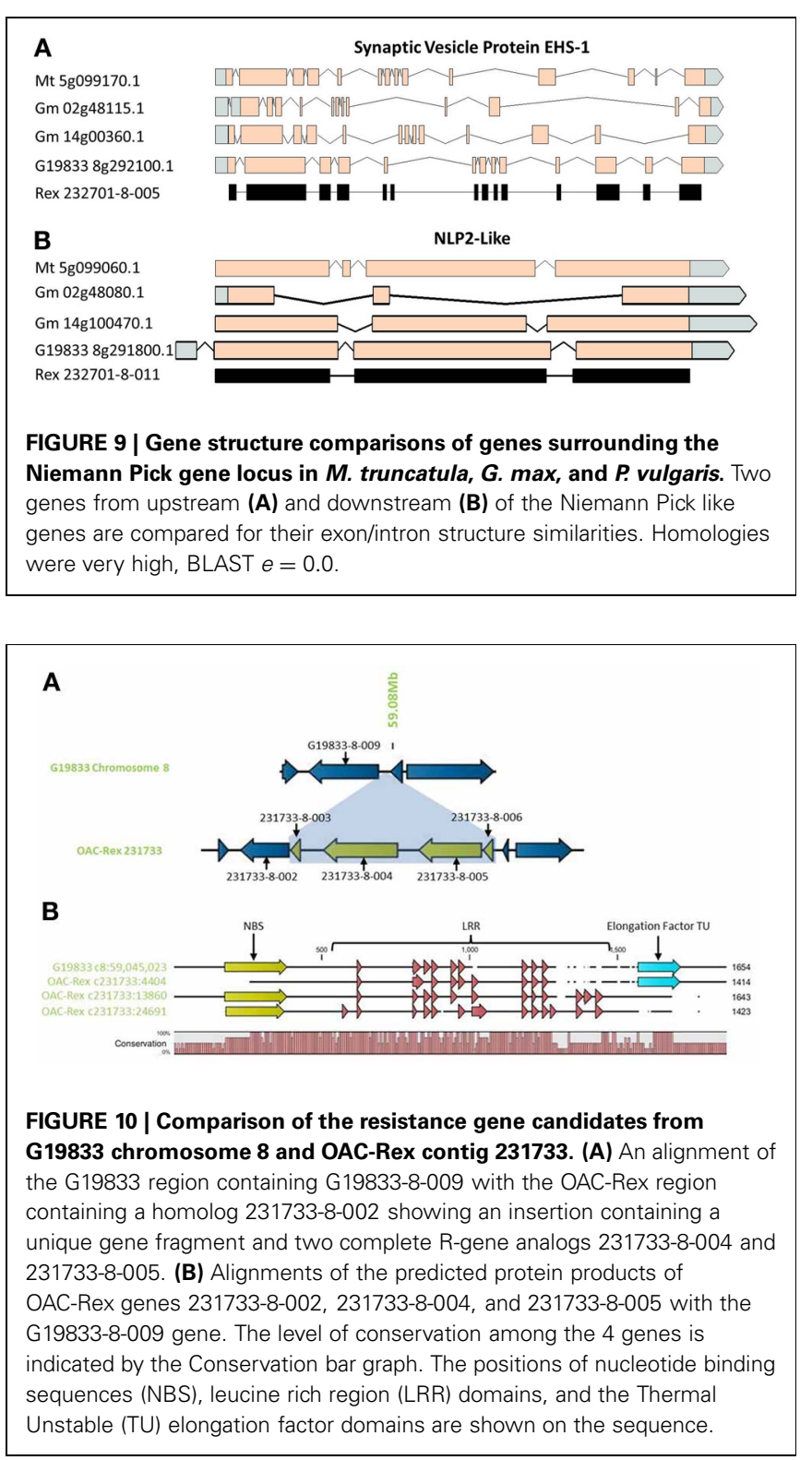

other unique gene cluster in OAC-Rex coincided resistance gene loci in contig 231733. Resistance gene clusters are known to undergo genomic duplication and rearrangement at higher frequencies than for most other regions of the genome (Meyers et al., 1998; Kim et al., 2009). Thus, it is possible that the unique genes in OAC-Rex in this regions may be the result of independent genetic rearrangements, rather than be signatures of introgression. However, the observation that the unique resistance genes were highly homologous to P. acutifolius ESTs in this region supports the suggestion that the unique genes were obtained by introgression from the interspecific parent (P. vulgaris $\times P$. acutifolius) in the OAC-Rex pedigree. However, the presence of genes with homology to P. acutifolius ESTs is not conclusive evidence for an insertion event, especially for resistance genes, as some of the resistance gene analogs in G19833 were also homologous to $P$. acutifolius genes. 
Generally, no function could be ascribed to the many of the unique genes identified in this study, with $31 \%$ of the annotated genes having no known function. However, they remain interesting targets for future analyses because of the possibility that they are of interspecific origin that may bring new traits to the cultivated dry bean. Additional data, perhaps from future transcriptional profiling, may provide insight into the biological roles of these genes.

\section{IDENTIFYING POTENTIAL CBB-RESISTANCE GENES IN OAC-REX}

Resistance derived from interspecific crosses in plants could arise through a number of mechanisms of gene modification associated with introgression, including: elevated transposable element activity (Liu and Wendel, 2000), altered gene methylation (Xiong et al., 2013), insertional mutagenesis (Hegarty and Hiscock, 2004) and novel gene introduction (Gill et al., 2011). Based on the hypothesis that CBB-resistance in OAC-Rex is due to the introgression of $P$. acutifolius DNA into the $P$. vulgaris genome, it is likely that genes unique to OAC-Rex will be responsible for this trait. Examples from the current study would include the two unique genes within the mapped SU91 resistance QTL on chromosome 8, in OAC Rex contig 232701.

The locus that is altered in OAC Rex and contains two genes (232701-8-007 and 232701-8-008) homologous to different portions of the Niemann Pick transporter in the G19833 genome. These two genes in the Niemann Pick transporter locus in OAC Rex could represent a loss-of-function mutation, where the gene function has been lost due to the 3000 bp insertion, or it may represent recombination with genes in P. acutifolius that have homology to this gene, but have independent functions. Structurally, the OAC-Rex genes appear to be derived from distinct regions of the G19833-8-080 gene, with the sterol sensing domain contained within 232701-8-007. Both OAC-Rex genes do appear to include a transmembrane domain; however, the traditional sterol sensing and transport role associated with the Niemann Pick transporters may not be preserved (Munkacsi et al., 2007). It is possible that OAC-Rex genes 232701-8-007 and 232701-8-008 have direct roles in defense against Xap, and that the deletion of G19833-8-080 in this variety was the result of a recombination event arising from the interspecific cross in its pedigree. Furthermore, the observation that the genes surrounding the Niemann-Pick loci in G19833 and OAC-Rex are homologous and share syntany with genes in other leguminous species (McConnell et al., 2010; Muchero et al., 2011), but the exon structure of the Niemann Pick-like genes in G19833-8-080, and OAC-Rex 232701-8-007, and 232701-8-008 are divergent, relative to the sequences from G. max and M. truncatula, may indicate that these genes are unique to $P$. vulgaris (Figure 6).

The function of the Niemann Pick transporter (NCP1) in mammalian cells is to transport of cholesterol from biliary micelles after absorption from the intestinal lumen, to the endoplasmic reticulum for conversion to cholesterol esters by acyl-CoA acyltransferase (Garver et al., 2002; Abi-Mosleh et al., 2009). Homologs of NPC1 have been identified across the animal and plant kingdoms (Munkacsi et al., 2007). In Arabidopsis, two Niemann Pick gene homologues have been identified, AT1G42470.1 and AT4G38350.1. Both of the proteins encoded by these genes have been localized to various regions of the cell, including: the plasma membrane (Benschop et al., 2007; Mitra et al., 2007), the vacuolar membrane (Carter et al., 2004; Jaquinod et al., 2007a,b) and the plasmodesmata (Fernandez-Calvino et al., 2011) Although there are difference in gene structure (Figure 6), given the degree of sequence conservation observed among the Niemann Pick genes across plant species it is likely that similar subcellular distributions occur for the Phaseolus Niemann Pick gene. But it is important to note that Niemann Pick gene function has not been studied in any plant species to date, and most of the functional analyses have focused on mammalian species but the conservation of the sterol binding motif in the G19833 Niemann Pick gene (and the 232701-8-007 OAC-Rex gene) suggest that they are also involved in sterol transport (Jang et al., 2000; Carter et al., 2004; Mitra et al., 2007). The complexity of phytosterol synthesis, compared to animal cholesterol synthesis, may account for the broad distribution of the Niemann Pick protein in plant membranes.

Given that there appears to only be one copy of the Niemann Pick gene in P. vulgaris, its disruption in OAC-Rex would be expected to knock out the function from the plant. Given the ubiquitous expression seen in the M. truncatula and G. max database (Benedito et al., 2008), it is possible that this protein fills a required niche in the cell. However, OAC-Rex does not exhibit any obvious negative phenotype, it can be concluded that the role of the Niemann Pick gene is either not essential for plant development, is accommodated by the action of a related protein, or is being fulfilled by the independent function(s) of the unique genes 232701-8-007 and 232701-8-008. Evidence for the independent function hypothesis is that both genes contain discrete transcription start sites and polyA signals, they are separated by $3 \mathrm{~kb}$ of intervening DNA and discrete $P$. acutifolius EST sequences homologous to both of the OAC-Rex genes have been previously identified in this study. Interestingly, disruption of sterol synthesis in Arabidopsis has been associated with an increase in basal resistance to bacterial infection. In particular, the stimulation of $\beta$-sisterol to stigmasterol conversion that is observed in Arabidopsis after infection by Pseudomonas syringae has been shown to increase the susceptibility of the plant to infection and inhibition of stigmasterol synthesis (in P450 CYP710A1 mutants) enhances plant resistance to avirulent and virulent $P$. syringae strains (Griebel and Zeier, 2010). The authors suggest that the plasma membranes, altered by the increased stigmasterol content, may have different pathogen perception or defense signaling properties. Perhaps if Niemann Pick gene(s) in G19833 and OAC-Rex play roles in sterol sensing, sterol transport/synthesis, and/or cell signaling pathways though brassinosteroids they are coupled to basal resistance in plants (for review see Clouse, 2002). Whatever their particular molecular role(s) are in plants, the example of the increase in resistance associated with the inhibition of stigmasterol synthesis, through the disruption of gene function, represents an interesting model for how an introgression event might result in increased resistance to $\mathrm{CBB}$ in beans.

The potential for these genes to represent non-traditional Rgene candidates is supported by previous studies involving G. max and H. vulgare. Comparative genomic analysis of the Rhg1 QTL 
in the $H$. glycines-resistant breeding line LD-09-15087a to the published Williams 82 genome indicated that copy number variation in genes from the rhg1-b interval were responsible for the resistance trait in the breeding line. The actual role of the genes is unknown at this time, but the authors hypothesized that the proteins are involved in intercellular transport in the roots (Cook et al., 2012).

In $H$. vulgare, another interesting model for non-traditional R-gene mediated resistance has been studied involving the involving 7TMR proteins. Previous research on a 7TMR gene from barley, called MLO (Jørgensen, 1992), showed that the disruption of this gene is associated with resistance to powdery mildew in barley and Arabidopsis, and also to resistance to bacterial pathogens, notably Pseudomonas syringae, Xanthomonas campesteris pv. vesicatoria and other type III secretions systempossessing bacteria in Capsicum annuum and Arabidopsis (Kim and Hwang, 2012; Lewis et al., 2012). In these systems the MLO encoded proteins are thought to repress the transport of material(s) required for papilla construction at the site of pathogen contact with the plant cell wall. When the functional allele is present, the transport of PENETRATION 2 (PEN2) and VESSICLE-ASSOCIATED MEMBRANE PROTEIN 722 (VAMP722) through PENETRATION 3 (PEN3) and the PENETRATION1/SYNAPTOSOMAL-ASSOCIATED PROTEIN 33 (PEN1/SNAP33) complex (Piffanelli et al., 2004) are prevented. Plants with a mutation in mlo are unimpeded in building a physical barrier against infection, and as a result, have a greater level of resistance to the pathogen. Given the taxonomic similarity between Xanthomonas and Pseudomonas genera (De Ley et al., 1966), it is reasonable to propose that similar resistance mechanisms could protect plants against both pathogens. Although the genes in G19833 or OAC-Rex do not appear to be close homologues for $M L O$, a similar mechanism may be operative in which replacement or modification of a gene required for pathogenicity is altered by introgression, thus allowing a basal defense response in OAC Rex.

The EGF-like proteins, like the one found in OAC-Rex (232701-8-016), are thought to play a role in cell wall expansion in plants, and are part of the wall associated kinase family (WAKs). In Arabidopsis, 22 WAKs have been identified, and they have the unique ability to convey signals from the cell wall to the cytosol (He et al., 1999; Silva and Goring, 2002). Additionally, WAK1 has been directly associated with pathogen defense against $P$. syringae in Arabidopsis (He et al., 1998). In wak 1 null mutants, infection with $P$. syringae maculicola ES4326 was lethal, and systemic acquired resistance did not function. Conversely, plants with a functional WAK1 survived infection. WAKs have a Ser/Thr kinase, an extracytoplasmic domain (ectodomain) with several EGF-like repeats that are thought to bind to Oligogalacturonides (OGs) released from the plant cell wall as a result of pathogen attack (Hendrickson et al., 2000). However, the gene in OAC Rex is much smaller than the Arabidopsis isoforms, with a predicted CDS of only $129 \mathrm{bp}$, as compared to AT3G52850.1 with a CDS of $1872 \mathrm{bp}$. Comparisons with other WAK genes from Oryza sativa did not show any significant homology to previously reported genes, thus indicating that this gene annotation does not encode for a functional protein (Silva and Goring, 2002). A similar comparison of the G19833 sequence from the same region did not indicate the presence of any EGF or WAK genes (data not shown).

In addition to the unique genes found within the mapped QTL, the 2 unique R-Gene candidates in Contig 231733, 232733 8-004, and 232-733-8-005, may also contribute to CBB-resistance in OAC Rex (Ellis et al., 2000). Although these resistance gene candidates are outside the main QTL for the resistance trait on chromosome 8, it is known that CBB-resistance is conditioned by several interacting loci (Gepts et al., 2008). At best, the major QTL usually account for $20-40 \%$ of the variation for resistance (Shi et al., 2012) leaving the possibility that more loci with small additive effects contribute to the full resistance observed in OAC Rex. The propensity of resistance gene clusters to contain unique genes in OAC-Rex, as seen in chromosome 8 (Figures 4, 10) could represent one mechanism for the introgression of new genetic material from an interspecific hybridization. The conservation of resistance gene features, combined with their tendency to occur in multi-gene clusters increases the likelihood for homologous recombination (Michaelmore and Meyers, 1998). When combined with a strong selective pressure from the breeding program, CBB-resistance in the case of OAC-Rex, the resistance gene clusters maintain a higher proportion of unique genes after interspecific hybridization. It is not known if these unique genes will play a direct role in disease resistance in OAC-Rex, but their conservation after backcrossing would indicate at worst a neutral contribution, and more likely a selective advantage (Barton, 1979; Baumgarten et al., 2003; Baack and Rieseberg, 2007; Gill et al., 2011).

The ability to compare genetic content, when combined with accurate mapping data can facilitate the discovery of the genetic sources of agronomic traits. In this study, two non-R-Gene candidates for CBB resistance were identified from Contig 231171 in OAC-Rex, and two R-gene candidates were discovered from Contig 231733. In the study of Shi et al. (2012), the CBBresistance QTL was mapped to a $430 \mathrm{~kb}$ region and 16 genes from the $32 \mathrm{H} 6 \mathrm{BAC}$ clone were examined to aid in the development of additional markers for the resistance QTL. The locations of the previously identified genes were confirmed in the present study (between 59,344,595 and 59,350,725 bp, data not shown) but the comparisons in this study showed that the genes in this region were conserved between G19833 and OAC-Rex, which reduces the likelihood that they are responsible for the resistance. The current approach, which is based on the identification of unique genes in the resistant variety greatly, reduces the number of gene candidates that would need to be individually assessed for the resistance trait. Future comparisons between G19833, OAC-Rex and $P$. acutifolius accessions are planned and will serve to further identify the regions of genetic introgression. Unfortunately, due to the difficulty in creating transgenics in P. vulgaris (Kwapata et al., 2012), it is unknown if current transgenic techniques can be successfully used in OAC-Rex, and further experiments will need to be conducted to determine this. However, examination of these genes in other resistant and susceptible lines will further aid in identifying one of the major genetic sources of $\mathrm{CBB}$ resistance in $P$. vulgaris. 


\section{CONCLUSIONS}

This study represents one of the first large scale comparisons of gene content between $P$. vulgaris lines. Overall gene order and orientation were highly conserved between G19833 and OAC-Rex across the regions examined. Our comparisons were somewhat hampered by the presence of $\mathrm{N}$-containing regions on chromosome 8 , and by a lack of genetic markers on chromosome 4, but comparisons for all three regions showed that $85 \%$ of the gene content was conserved between the two lines in the same physical space. This value did vary between $80 \%$ for the SAP6 fragment on chromosome 10, to $90 \%$ for the SU91 fragment from chromosome 8 , but conserved regions were generally found in large stretches. Interestingly, unique genes were found interspersed throughout the conserved sequences, with novel genes generally occurring individually or in pairs. Exceptions to this were found in regions associated with high genetic variability, such as the resistance gene clusters on chromosome 8 and 10, but the lack of any large unique regions would indicate that landmarks for interspecific introgression events cannot be inferred by the proportion of novel content alone. The identification of 2 Niemann Pick genes from OAC-Rex contig 232701, and two resistance gene candidates from contig 231733 have shown the potential for comparative genomics to identify novel gene content from hybridizations, and can accelerate the search for unique genes. Future analyses on these gene candidates will be conducted

\section{REFERENCES}

Abi-Mosleh, L., Infante, R. E., Radhakrishnan, A., Goldstein, J. L., and Brown, M. S. (2009). Cyclodextrin overcomes deficient lysosome-to-endoplasmic reticulum transport of cholesterol in Niemann-Pick type C cells. Proc. Natl. Acad. Sci. 106, 19316-19321. doi: 10.1073/pnas.0910916106

Andrew, R. L., Kane, N. C., Baute, G. J., Grassa, C. J., and Rieseberg, L. H. (2012). Recent nonhybrid origin of sunflower ecotypes in a novel habitat. Mol. Ecol. 22, 799-813. doi: 10.111/ mec. 12038

Arnold, M. L., Bouck, A. C., and Cornman, R. S. (2003). Verne grant and Louisiana irises: is there anything new under the sun? New Phytol. 161, 143-149. doi: 10.1046/j.1469-8137.2003.00856.x

Baack, E. J., and Rieseberg, L. H. (2007). A genomic view of introgression and hybrid speciation. Curr. Opin. Genet. Dev. 14, 513-518. doi: 10.1016/j.gde.2007.09.001

Barton, N. H. (1979). Gene flow past a cline. Heredity 43, 333-339. doi: 10.1038/hdy.1979.86

Baumgarten, A., Cannon, S., Spangler, R., and May, G. (2003). Genomelevel evolution of resistance genes in Arabidopsis thaliana. Genetics 165, 309-319.
Benedito, V. A., Torres-Jerez, I., Murray, J. D., Andriankaja, A., Allen, S., Kakar, K., et al. (2008). A gene expression atlas of the model legume Medicago truncatula. Plant J. 55, 504-513. doi: 10.1111/j.1365-313X.2008.03519.x

Benschop, J. J., Mohammed, S., O'Flaherty, M., Heck, A. J. R., Slijper, M., and Menke, F. L. H. (2007). Quantitative phosphoproteomics of early elicitor signalling in Arabidopsis. Mol. Cell. Proteomics 6, 1198-1214. doi: 10.1074/mcp.M600429-MCP200

Bitocchi, E., Nanni, L., Bellucci, E., Rossi, M., Giardini, A., Zeuli, P. S., et al. (2012). Mesoamerican origin of the common bean (Phaseolus vulgaris L) is revealed by sequence data. Proc. Natl. Acad. Sci. U.S.A. 109, E788-E796. doi: 10.1073/pnas.1108973109

Buell, C. R. (2002). "Interactions between Xanthomonas species and Arabidopsis thaliana," in The Arabidopsis Book. American Society of Plant Biologists, eds C. R. Somerville and E. M. Meyerowitz (Rockville, MD: American Society of Plant Biologists), 1:e0031. doi: 10.1199/tab.0031

Cao, J., Schneeberger, K., Ossowski, J., et al. (2011). Whole-genome sequencing of multiple Arabidopsis S., Günther, T., Bender, S., Fitz,

to determine if the genes identified in this study contribute to $\mathrm{CBB}$ resistance in OAC-Rex.

The results of this study serve as an important starting point for the examination of gene syntany in $P$. vulgaris. Aside from the direct application of syntenic analyses for identifying genes associated with important agronomic traits, future studies examining genome variation at whole genome levels in addition to localized comparisons of genetic variability within individual genes will provide valuable insights into the evolution of the $P$. vulgaris market classes.

\section{ACKNOWLEDGMENTS}

The authors of this paper would like to thank the members of the BeanCAP group, David L. Hyten, Qijian Song, Edward W. Fickus, Charles V. Quigley, Jong-Sung Lim, Ik-Young Choi, EunYoung Hwang, Marcial Pastor-Corrales, and Perry B. Cregan, for granting us the use of their SNP markers for our analysis. We would also like thank Sergio Pereira and the staff at the Centre for Applied Genomics for their contribution to the next generation sequencing of OAC-Rex.

\section{SUPPLEMENTARY MATERIAL}

The Supplementary Material for this article can be found online at: http://www.frontiersin.org/Plant_Genetics_and_Genomics/ 10.3389/fpls.2013.00318/abstract

thaliana populations. Nat. Genet. 43, 956-963. doi: 10.1038/ng.911

Carstea, E. D., Morris, J. A., Coleman, K. G., Loftus, S. K., Zhang, D., Cummings, C., et al. (1997). Niemann-Pick $\mathrm{Cl}$ disease gene: homology to mediators of cholesterol homeostasis. Science 277, 228-231. doi: 10.1126/science.277.5323.228

Carter, C., Pan, S., Zouhar, J., Avila, E. L., Girke, T., and Raikhel, N. V. (2004). The vegetative vacuole proteome of Arabidopsis thaliana reveals predicted and unexpected proteins. Plant Cell 16, 3285-3303. doi: $10.1105 /$ tpc.104.027078

Clouse, S. D. (2002). Arabidopsis mutants reveal multiple roles for sterols in plant development. Plant Cell 14, 1995-2000. doi: 10.1105/tpc. 140930

Consonni, C., Humphry, M. E., Hartmann, H. A., Livaja, M., Durner, J., Westphal, L., et al. (2006). Conserved requirement for a plant host cell protein in powdery mildew pathogenesis. Nat. Genet. 38, 716-720. doi: 10.1038/ng1806

Cook, D. E., Lee, T. G., Gue, X., Melito, S., Wang, K., Bayless, A. M., et al. (2012). Copy number variation of multiple genes ar RHG1 mediates nematode resistance in soybean. Science 338, 1206-1209. doi: $10.1126 /$ science. 1228746
Debouck, D. G., Toro, O., Paredes, O. M., Johnson, W. C., and Gepts, P. (1993). Genetic diversity and ecological distribution of Phaseolus vulgaris in north-western South America. Econ. Bot. 47, 408-423. doi: 10.1007/BF02907356

De Ley, J., Park, W., Tijtgat, R., and Van Ermengem, J. (1966). DNA homology and taxonomy of Pseudomonas and Xanthomonas. J. Gen. Microbiol. 42, 43-56. doi: 10.1099/00221287-42-1-43

Durham, K. M. (2011). Evaluation of Common Bacterial Blight Resistance in a Resistant Inter-Cross Population of Common Bean. M.Sc. thesis, University of Guelph.

Durham, K. M., Xie, W., Yu, K., Pauls, K. P., Lee, E., and Navabi, A. (2013). Interaction of common bacterial blight quantitative trait loci in a resistant inter-cross population of common bean. Plant Breeding. doi: 10.1111/pbr.12103. [Epub ahead of print].

Ellis, J., Dodds, P., and Pryor, T. (2000). Structure, function and evolution of plant disease resistance genes. Curr. Opin. Plant Biol. 3, 278-284. doi: 10.1016/S1369-5266 (00)00080-7

Evans, A. M. (1973). “Genetic improvement of Phaseolus vulgaris," in Nutritional Improvement of Food Legumes by Breeding, ed M. Milner 
(New York, NY: John Wiley \& Sons Inc), 107-115.

Fernandez-Calvino, L., Faulkner, C., Walshaw, J., Saalbach, G., Bayer, E., Benitez-Alfonso, Y., et al. (2011). Arabidopsis plasmodesmal proteome. PLoS ONE 6:e18880. doi: 10.1371/journal.pone.0018880

Finn, R. D., Tate, M. J., Coggill, P., Heger, A., Pollington, J. E., Gavin, O. L., et al. (2010). The Pfam protein families database. Nucleic Acids Res. 38, D211-D222. doi: 10.1093/nar/gkp985

Garver, W. S., Krishnan, K., Gallagos, J. R., Michikawa, M., Francis, G. A., and Heidenreich, R. A. (2002). 20. Niemann Pick C1 protein regulates cholesterol transport to the trans-Golgi network and plasma membrane caveolae. J. Lipid Res. 43, 579-589.

Gepts, P., Aragão, F., Barros, E., Blair, M. W., Brondani, R., Broughton, W., et al. (2008). "Genomics of Phaseolus beans, a major source of dietary protein and micronutrient in the Tropics," in Genomics of Tropical Crop Plants, eds P. H. Moore and R. Ming (Berlin: Springer), 113-143. doi: 10.1007/978-0-387-71219-2_5

Gill, B. S., Friebe, B. R., and White, F. F. (2011). Alien introgressions represent a rich source of genes for crop improvement. Proc. Natl. Acad. Sci. U.S.A. 108, 7657-7658. doi: 10.1073/pnas.1104845108

Griebel, T., and Zeier, J. (2010). A role for B-sitosterol to stigmasterol conversion in plant-pathogen interactions. Plant J. 63, 254-268. doi: 10.1111/j.1365-313X.2010.04235.x

Hayward, A. C., and Waterston, J. M. (1965). "Xanthomonas phaseoli Var. Fuscans. CMI Descriptions of Pathogenic Fungi and Bacteria No. 49. Wallingford, UK: CAB International.

He, Z. H., Cheeseman, I., He, D., and Kohorn, B. D. (1999). A cluster of five cell wall-associated receptor kinase genes, Wak1-5, are expressed in specific organs of Arabidopsis. Plant Mol. Biol. 39, 1189-1196. doi: 10.1023/A:1006197318246

He, Z. H., He, D., and Kohorn, B. D. (1998). Requirement for the induced expression of a cell wall associated receptor kinase for survival during the pathogen response. Plant J. 14, 55-63. doi: 10.1046/j.1365-313X. 1998.00092.x

Hegarty, M. J., and Hiscock, S. J. (2004). Hybrid speciation in plants: new insights from molecular studies. New Phytologist 165, 411-423. doi: 10.1111/j.1469-8137.2004.01253.x
Hendrickson, E. L., Guevera, P., Peñaloza-Vàzquez, A., Shao, J., Bender, C., and Ausubel, F. M. (2000). Virulence of the phytopathogen Pseudomonas syringae pv. maculicola is rpoN dependent. J. Bacteriol. 182, 3498-3507. doi: 10.1128/JB.182.12.3498-3507.2000

Hufford, M. B., Lubinksy, P., Pyhajarvi, T., Devengenzo, M. T., Ellstrand, N. C., and Ross-Ibarra, J. (2013). The genomic signature of cropwild introgression in maize. PLoS Genet. 9:e1003477. doi: 10.1371/journal.pgen.1003477

Hyten, D. L., Song, Q., Fickus, E. W., Quigley, C. V., Lim, J. S., Choi, I. Y., et al. (2010). High-throughput SNP discovery and assay development in common bean. BMC Genomics 11:475 doi: 10.1186/1471-2164-11475

Jang, J. C., Fujioka, S., Tasaka, M., Seto, H., Takatsuto, S., Ishii, A., et al. (2000). A critical role of sterols in embryonic patterning and meristem programming revealed by the fackel mutants of Arabidopsis thaliana. Genes Dev. 14, 1485-1497.

Jaquinod, M., Villiers, F., KiefferJaquinod, S., Hugouvieux, V., Bruley, C., Jerome, G., et al. (2007a). A proteomics approach highlights a myriad of transporters in the Arabidopsis thaliana vacuolar membrane. Plant Signal. Behav. 2, 413-415. doi: 10.4161/psb.2.5.4415

Jaquinod, M., Villiers, F., KiefferJaquinod, S., Hugouvieux, V., Bruley, C., Garin, J., et al. (2007b). A proteomics dissection of Arabidopsis thaliana vacuoles isolated from cell culture. Mol. Cell. Proteomics 6, 394-412. doi: 10.1074/mcp.M600250-MCP200

Jørgensen, J. H. (1992). Discovery, characterization and exploitation of Mlo powdery mildew resistance in barley. Euphytica 63, 141-152. doi: 10.1007/ BF00023919

Kawapata, K., Nguyen, T., and Sticklen, M. (2012). Genetic transformation of common bean (Phaseolus vulgaris L.) with the gus color marker, the bar herbicide resistance, and the barley (Hordeum vulgare) HVAl drought tolerance genes. Int. J. Agron. 2012, 198960. doi: $10.1155 / 2012 / 198960$

Kim, D. S., and Hwang, B. K. (2012). The pepper MLO gene, CaMLO2, is involved in the susceptibility cell-death response and bacterial an oomycete proliferation. Plant J. 72, 843-855. doi: 10.1111/ tpj.12003

Kim, K. D., Shin, J. H., Van, K., Kim, D. H., and Lee, S. (2009).
Dynamic rearrangements determine genome organization and useful traits in soybean. Plant Physiol. 151, 1066-1076. doi: 10.1104/pp.109.141739

Koening, R., and Gepts, P. (1989). Allozyme diversity in wild Phaseolus vulgaris: further evidence for two major centers of diversity. Theor. Appl. Genet. 78, 809-817.

Koening, R. L., Singh, S. P., and Gepts, P. (1990). Novel phaseolin types in wild and cultivated common bean (Phaseolus vulgaris, Fabaceae). Econ. Bot. 44, 50-60. doi: 10.1007/BF02861066

Krogh, A., Larsson, B., von Heijne, G., and Sonnhammer, E. L. L. (2001). Predicting transmembrane protein topology with a Hidden Markov Model: Application to complete genomes. J. Mol. Biol. 305, 567-580. doi: 10.1006/jmbi.2000.4315

Kwapata, K., Nguyen, T., and Sticklen, M. (2012). Genetic transformation of common bean (Phaseolus vulgaris L.) with the gus color marker, the bar herbicide resistance, and the barley (Hordeum vulgare) HVAl drought tolerance genes. Int. J. Agron. 2012:198960. doi: 10.1155/2012/ 198960

Lewis, J. D., Wan, J., Ford, R., Gong, Y., Fung, P., Nahal, H., et al. (2012). Quantitative Interactor Screening with next-generation Sequencing (QIS-Seq) identifies Arabidopsis thaliana MLO2 as a target of the Pseudononas syringae type III effector HopZ2. BMC Genomics 13:8. doi: 10.1186/1471-2164-13-8

Leyns, F., De Cleene, M., Swings, J., and De Ley, J. (1984). The host range of the genus Xanthomonas. Bot. Rev. 50, 308-355.

Liu, B., and Wendel, J. F. (2000). Retrotransposon activation followed by rapid repression in introgressed rice plants. Genome 43 , 874-880.

Lu, G., Wang, Z., Jones, A. M., and Moriyama, E. M. (2009). 7TMRmine: a Web server for hierarchical mining of 7TMR proteins. BMC Genomics 10:275. doi: 10.1186/1471-2164-10-275

McConnell, M., Mamidi, S., Lee, R., Chikara, S., Rossi, M., Papa, R., et al. (2010). Syntenic relationship among legumes revealed using a gene-based genetic linkage map of common bean (Phaseolus vulgaris L.) Theor. Appl. Genet. 121, 1103-1116. doi: 10.1007/s00122-010-1375-9

Meyers, B. C., Chin, D. B., Shen, K. A., Sivaramakrishanan, S., Lavelle, D. O., Zhang, Z., et al. (1998). The major resistance gene cluster in lettuce is highly duplicated and spans several megabases. Plant Cell 10, 1817-1832.

Michaelmore, R. W., and Meyers, B. C. (1998). Clusters of resistance genes in plants evolve by divergent selection and a birth-and-death process. Genome Res. 8, 1113-1130.

Michaels, T. E., Smith, T. W., Larsen, J., Beattie, A. D., and Pauls, K. P. (2006). OAC Rex common bean. Can. J. Plant Sci. 86, 733-736. doi: 10.4141/P05-128

Miklas, P. N., Delorme R., and Riley R. (2003). Identification of QTL conditioning resistance to white mold in a snap bean population. J. Am. Soc. Hortic. Sci. 128, 564-570.

Miklas, P. N., Beaver, J. S., Grafton, K. F., and Freytag, G. F. (1994). Registration of TARS VCI-4B multiple disease resistant dry bean germplasm. Crop Science 34, 1415. doi: 10.2135/cropsci1994.0011183X003400050065x

Mitra, S. K., Gantt, J. A., Ruby, J. F., Clouse, S. D., and Goshe, M. B. (2007). Membrane proteomic analysis of Arabidopsis thaliana using alternative solubilization techniques. J. Proteome Res. 6, 1933-1950. doi: 10.1021/pr060525b

Muchero, W., Ehlers, J. D., Close, T. J., and Roberts, P. A. (2011). Genic SNP markers and legume synteny underlying QTL for Macrophomina phaseolina resistance and maturity in cowpea [Vigna unguiculata (L) Walp]. BMC Genomics 12:8. doi: 10.1186/1471-2164-12-8

Munkacsi, A. B., Porto, A. F., and Sturley, S. L. (2007). Niemann Pick type C disease proteins: orphan transporters or membrane rheostats? Future Lipidol. 2, 357-367. doi: 10.2217/17460875.2.3.357

Nakamoto, T. (2009). Evolution and the universality of the mechanism of initiation of protein synthesis. Gene 432, 1-6. doi: 10.1016/j.gene.2008.11.001

Park, S. J., and Dhanvantari, B. N. (1987). Transfer of common bean blight (Xanthomonas campestris pv. phaseoli) resistance from Phaseolus coccineus Lam. to P. vulgaris $\mathrm{L}$. through interspecific hybridization. Can. J. Plant Sci. 67, 685-695. doi: 10.4141/cjps87-096

Park, S. J., and Dhanvantari, B. N. (1994). Registration of common bean blight-resistant Germplasm, HR45. Crop Science 34, 548. doi: 10.2135/cropsci1994.0011183X003400020065x

Parker, J. P. K. (1985). Interspecific Transfer of Common Bacterial 
Blight Resistance From Phaseolus Acutifolius A. Gray to Phaseolus Vulgaris L. M.Sc. thesis, University of Guelph.

Perry, G., and Pauls, K. P. (2012). "Common bacterial blight in Phaseolus vulgaris," in Agricultural Research Updates, Vol. 2, ed B. Hendricks (Hauppage, NY: Nova Science Publishers), 239-264.

Piffanelli, P., Ramsey, L., Waugh, R., Benabdelmouna, A., D'Hont, A., Hollricher, K., et al. (2004). A barley cultivation-associated polymorphism conveys resistance to powdery mildew. Nature 430, 887-891. doi: $10.1038 /$ nature 02781

Ramirez, M., Graham, M. A., BlancoLopez, L., Silvente, S., MedranoSoto, A., Blair, M. W., et al. (2005). Sequencing and analysis of common bean ESTs. Building a foundation for functional genomics. Plant Physiol. 137, 112-1227. doi: 10.1104/pp.104.054999

Riesberg, L. H., Raymond, O., Rosenthal, D. M., Lai, Z., Livingstone, K., Nakazato, T., et al. (2003). Major ecological transitions in wild sunflowers facilitated by hybridization. Science 301, 1211-1216. doi: 10.1126/science. 1086949

Schneeberger, K., Ossowski, S., Ott, F., Klein, J. D., Wang, X., Lanz, C., et al. (2011). Reference-guided assembly of four diverse Arabidopsis thaliana genomes. Proc. Natl. Acad. Sci. U.S.A. 108, 10249-10254. doi: 10.1073/pnas.1107739108

Schuleter, J. A., Goicoechea, J. L., Collura, K., Gill, N., Lin, J. Y., Yu, Y., et al. (2008). BAC-end-sequence analysis and a draft physical map of the common bean (Phaseolus vulgaris L.). Trop. Plant Biol. 1, 40-48. doi: 10.1007/s12042-007-9003-9
Scott, M. E., and Michaels, T. E. (1992). Xanthomonas resistance of Phaseolus interspecific cross selections confirmed by field performance. HortScience 27, 348-350.

Shi, C., Navabi, A., and Yu, K. (2011). Association mapping of common bacterial blight resistance QTL in Ontario bean breeding populations. BMC Plant Biol. 11:52. doi: 10.1186/1471-2229-11-52

Shi, C., Yu, K., Xie, W., Perry, G. E., Navabi, A., Pauls, K. P., et al. (2012). Development of candidate gene markers associated to common bacterial blight resistance in common bean. Theor. Appl. Genet. 125, 1525-1537. doi: 10.1007/s00122012-1931-6

Silva, N. F., and Goring, D. R. (2002). The proline-rich, extensin-like receptor kinase-1 (PERK1) gene is rapidly induced by wounding. Plant Mol. Biol. 50, 667-685. doi: 10.1023/A:1019951120788

Singh, S. P., Gepts, P., and Debouck, D. G. (1991). Races of common bean (Phaseolus vulgaris L., Fabaceae). Econ. Bot. 45, 379-396. doi: 10.1007/BF02887079

Singh, S. P., and Schwartz, H. F. (2010). Breeding common bean for resistance to diseases: A review. Crop Science 50, 2199-2223. doi: 10.2135/cropsci2009.03.0163

Starr, M. P. (1981). "The genus Xanthomona," in The Procaryotes, eds M. P. Starr, H. Stolp, H. G. B. Trüper, A. Balows, and H. G. Schlegel (Berlin: Springer-Verlag), 742-763.

Tar'an, B., Michaels, T. E., and Pauls, K. P. (2001). Mapping genetic factors affecting the reaction to Xanthomonas axonopodis pv. phaseoli in Phaseolus vulgaris L. under field conditions. Genome 44, 1046-1056.

Vandermark, G. J., Fourie, D., and Miklas, P. N. (2008). Genotyping with real-time PCR reveals recessive epistasis between independent QTL conferring resistance to common bacterial blight in dry bean. Theor. Appl. Genet. 117, 531-522.

Verica, J. A., and He, Z. H. (2002). The cell wall-associated kinase (WAK) and WAK-like kinase gene family. Plant Physiol. 129, 455-459. doi: 10.1104/pp.011028

Wagner, T. A., and Kohorn, B. D. (2001). Wall-associated kinases are expressed throughout plant development and are required for cell expansion. Plant Cell 13, 303-318.

Wheeler, D. A., Srinivasan, M., Egholm, M., Shen, Y., Chen, L., McGuire, A., et al. (2008). The complete genome of an individual by massively parallel DNA sequencing. Nature 452, 872-876. doi: 10.1038/nature06884

Xiong, W., Li, X., Fu, D., Mei, J., Li, Q., Lu, G., et al. (2013). DNA Methylation Alterations at $5^{\prime}$ CCGG Sites in the Interspecific and Intraspecific Hybridizations Derived from Brassica rapa and B. napus. PLoS ONE 8:e65946. doi: 10.1371/journal.pone.0065946

Yu, K., Park, S. J., Zhang, B., Haffner, M., and Poysa, V. (2004). An SSR marker in the nitrate reductase gene of common bean is tightly linked to a major gene conferring resistance to common bacterial blight. Euphytica 138, 89-95. doi: 10.1023/B:EUPH.0000047077. 75285.60

Yun, M. H., Torres, P. S., Oirdi, M. E., Rigano, L. A., Gonzales-Lamothe, R., Marano, M. R., et al. (2006).
Xanthan induces plant susceptibility by suppressing callose deposition. Plant Physiol. 141, 178-187. doi: 10.1104/pp.105. 074542

Zhang, H. B., Zhao, X. P., Paterson, A. H., and Wing, R. A. (1995). Preparation of megabase DNA from plant nuclei. Plant J. 7, 175-184. doi: 10.1046/j.1365313X.1995.07010175.x

Conflict of Interest Statement: The authors declare that the research was conducted in the absence of any commercial or financial relationships that could be construed as a potential conflict of interest.

Received: 25 May 2013; accepted: 29 July 2013; published online: 29 August 2013. Citation: Perry G, DiNatale C, Xie W, Navabi A, Reinprecht Y, Crosby W, Yu K, Shi C and Pauls KP (2013) A comparison of the molecular organization of genomic regions associated with resistance to common bacterial blight in two Phaseolus vulgaris genotypes. Front. Plant Sci. 4:318. doi: 10.3389/fpls.2013.00318 This article was submitted to Plant Genetics and Genomics, a section of the journal Frontiers in Plant Science.

Copyright (c) 2013 Perry, DiNatale, Xie, Navabi, Reinprecht, Crosby, Yu, Shi and Pauls. This is an open-access article distributed under the terms of the Creative Commons Attribution License (CC BY). The use, distribution or reproduction in other forums is permitted, provided the original author(s) or licensor are credited and that the original publication in this journal is cited, in accordance with accepted academic practice. No use, distribution or reproduction is permitted which does not comply with these terms. 